\title{
On the stability of a variety of organic photovoltaic devices by IPCE and in situ IPCE analyses - the ISOS-3 inter-laboratory collaboration $\dagger$
}

\author{
Gerardo Teran-Escobar, ${ }^{a}$ David M. Tanenbaum, ${ }^{b c}$ Eszter Voroshazi, ${ }^{d}$ \\ Martin Hermenau, ${ }^{e}$ Kion Norrman, ${ }^{b}$ Matthew T. Lloyd, ${ }^{f}$ Yulia Galagan, ${ }^{g}$ \\ Birger Zimmermann, ${ }^{h}$ Markus Hösel, ${ }^{b}$ Henrik F. Dam, ${ }^{b}$ Mikkel Jørgensen, ${ }^{b}$ \\ Suren Gevorgyan, ${ }^{b}$ Suleyman Kudret, ${ }^{i}$ Wouter Maes, ${ }^{i}$ Laurence Lutsen, ${ }^{j}$ \\ Dirk Vanderzande, ${ }^{i}$ Uli Würfel, ${ }^{h}$ Ronn Andriessen, ${ }^{g}$ Roland Rösch, ${ }^{k}$ \\ Harald Hoppe, ${ }^{k}$ Agnès Rivaton, ${ }^{l}$ Gülşah Y. Uzunoğlu, ${ }^{m}$ David Germack, ${ }^{n}$ \\ Birgitta Andreasen, ${ }^{b}$ Morten V. Madsen, ${ }^{b}$ Eva Bundgaard, ${ }^{b}$ Frederik C. Krebs ${ }^{b}$ and \\ Monica Lira-Cantu*a
}

Received 15th March 2012, Accepted 21st May 2012

DOI: $10.1039 / \mathbf{c} 2 \mathrm{cp} 40821 \mathrm{j}$

This work is part of the inter-laboratory collaboration to study the stability of seven distinct sets of state-of-the-art organic photovoltaic (OPV) devices prepared by leading research laboratories. All devices have been shipped to and degraded at RISØ-DTU up to 1830 hours in accordance with established ISOS-3 protocols under defined illumination conditions. In this work, we apply the Incident Photon-to-Electron Conversion Efficiency (IPCE) and the in situ IPCE techniques to determine the relation between solar cell performance and solar cell stability. Different ageing conditions were considered: accelerated full sun simulation, low level indoor fluorescent lighting and dark storage. The devices were also monitored under conditions of ambient and inert $\left(\mathrm{N}_{2}\right)$ atmospheres, which allows for the identification of the solar cell materials more susceptible to degradation by ambient air (oxygen and moisture). The different OPVs configurations permitted the study of the intrinsic stability of the devices depending on: two different ITO-replacement alternatives, two different hole extraction layers (PEDOT:PSS and $\mathrm{MoO}_{3}$ ), and two different P3HT-based polymers. The response of un-encapsulated devices to ambient atmosphere offered insight into the importance of moisture in solar cell performance. Our results demonstrate that the IPCE and the in situ IPCE techniques are valuable analytical methods to understand device degradation and solar cell lifetime.

\section{Introduction}

Organic photovoltaics (OPVs) have reached a mature stage, with power conversion efficiencies (PCE) of around $8-10 \%$.
Further steps towards the development of large-area OPVs require highly stable devices with long lifetimes. In order to improve OPV stability it is important to understand the

${ }^{a}$ Centre d'Investigacióen Nanociència i Nanotecnologia (CIN2, CSIC), Laboratory of Nanostructured Materials for Photovoltaic Energy,

ETSE, Campus UAB, Edifici Q, 2nd floor, E-08193, Bellaterra, Barcelona, Spain. E-mail: monica.lira@cin2.es

${ }^{b}$ Department of Energy Conversion and Storage, Technical University of Denmark, Frederiksborgvej 399, DK-4000, Roskilde, Denmark

${ }^{c}$ Department of Physics and Astronomy, Pomona College, Claremont, CA 91711, USA

${ }^{d}$ IMEC, Kapeldreef 75, 3000 Leuven, Belgium and Katholieke Universiteit Leuven, ESAT, Kasteelpark Arenberg 10, 3000, Leuven, Belgium

e Arbeitsgruppe Organische Solarzellen (OSOL), Institut für Angewandte Photophysik, Technische Universität Dresden, 01062, Dresden, Germany

${ }^{f}$ National Renewable Energy Laboratory, Golden, CO 80401, USA

${ }^{g}$ Holst Centre, High Tech Campus 31, 5656 AE, Eindhoven, The Netherlands

${ }^{h}$ Fraunhofer Institute for Solar Energy Systems ISE, Heidenhofstrasse 2, D-79110, Freiburg, Germany

${ }^{i}$ Hasselt University, Campus, Agoralaan 1, Building D, WET/OBPC, B-3590, Diepenbeek, Belgium

${ }^{j}$ IMEC, IMOMEC Associated Laboratory, Campus University of Hasselt, Wetenscharpspark 1, B-3590, Diepenbeek, Belgium

${ }^{k}$ Institute of Physics, Ilmenau University of Technology, Weimarer Str. 32, E98693, Ilmenau, Germany

${ }^{l}$ Clermont Université, Université Blaise Pascal, Laboratorie de Photochemie, Moléculaire et Macromoléculaire (LPMM),

BP10448 Clermont-Ferrand, France and CNRS, UMR6505, LPMM, F-63177, Aubière, France

${ }^{m}$ TÜBITAK National Metrology Institute (UME), Photonic and Electronic Sensors Laboratory, P.O. Box 54, 41470, Gebze, Kocaeli, Turkey

${ }^{n}$ Condensed Matter Physics, Brookhaven National Lab, Building 510B Upton, NY 11973, USA

$\dagger$ Electronic supplementary information (ESI) available: See DOI: $10.1039 / \mathrm{c} 2 \mathrm{cp} 40821 \mathrm{j}$ 
different degradation mechanisms, and many characterization techniques have been applied to this purpose. This work is part of a series of publications from the research collaboration established at the Third International Summit on Organic Photovoltaic Stability (ISOS-3). Seven distinct state-of-the-art OPV devices were prepared by leading research laboratories (NREL, IMEC, HOLST, ISE, RISØ and IAPP). The devices were aged under different degradation conditions: accelerated full sun simulation, low level indoor fluorescent lighting and dark storage. Our first publication deals with the overall degradation behaviour of the devices by reporting on the changes observed in power conversion efficiency with aging time. $^{2}$ The second report deals with the analysis of the degradation of the solar cells by combining different characterization techniques such as laser beam induced current (LBIC), dark lock-in thermography imaging (DLIT), electroluminescence (ELI) and photoluminescence imaging (PLI). ${ }^{3}$ In this third publication, we apply the Incident Photon-toElectron Conversion Efficiency (IPCE) and in situ IPCE techniques as tools to analyze the different degradation paths observed in the OPV devices. The IPCE, also known as Quantum Efficiency (QE), is defined as the number of charge carriers collected by the solar cell depending on the number of photons of a given energy adsorbed by the device. It is given in terms of energy or wavelength, and it depends on several aspects of the solar cell, like the absorption coefficient of the materials applied, the efficiency of the charge separation and charge collection. ${ }^{4}$ Since it is independent of the incident light spectrum, it is a useful tool to analyze solar cell response under different conditions. An IPCE spectrum can be considered as the fingerprint of an OPV since almost each material present in the solar cell can be identified by the corresponding peak at a given wavelength. The changes observed in any of the IPCE peaks indicate the solar cell materials that are more susceptible to degradation at the given testing condition. This technique presents several advantages since it is a nondestructive method and a basic analytical technique found at almost any photovoltaic laboratory. Its application can give initial insight into the possible degradation paths of a solar cell without the application of complicated analytical methodologies. The work presented here is divided into 4 main sections (see Results and Discussion). To facilitate the comprehension of the work, the sections are written independently of each other, and the reader is directed to any other section when necessary. In the first section we identify and describe the different IPCE peaks observed for each reference device (Section 3.1). The following sections (3.2 to 3.4) describe the results of the stability tests carried out on the devices (accelerated full sun simulation, low level indoor fluorescent lighting or dark storage) depending on the type of encapsulation used for the devices. Thus, the second section encompasses the glass encapsulated devices (IAPP, HOLST and ISE devices), the 3rd section the semiencapsulated devices in plastic (RISØ-P and RISØ-S) and finally, the 4th section, the un-encapsulated devices (IMEC and NREL). Our results give insight into the intrinsic stability of the solar cells with two ITO-free alternatives (HOLST and ISE), two different P3HT polymers (RISØ-P and RISØ-S) and the stability under ambient air depending on two different hole extraction layers like PEDOT and $\mathrm{MoO}_{3}$ (NREL and IMEC).

\section{Experimental}

\subsection{Devices}

The photovoltaic devices were prepared by various collaborators within the consortium according to the round robin discussion group and planning at the ISOS-3 workshop. The devices were prepared by six different groups: the Institute of Applied PhotoPhysics in Dresden, Germany (IAPP), the Interuniversity MicroElectronics Centre in Leuven, Belgium (IMEC), the National Renewable Energy Laboratory in Golden, Colorado (NREL), the HOLST centre in Eindhoven, The Netherlands (HOLST), the Fraunhofer Institute for Solar Energy Systems in Freiburg, Germany (ISE), and the Department of Energy Conversion and Storage, Technical University of Denmark (RISØ-DTU). Fig. 1 displays all investigated devices true to scale. The details of the preparation and architecture of the photovoltaic devices investigated within this collaboration can be found within the first article of this series. ${ }^{2}$ In brief, all devices utilize the bulk heterojunction architecture for the photoactive layer. The material system in the case of vacuum processing was based on zinc-phthalocyanine:fullerene (ZnPc: $\mathrm{C}_{60}$ ), in all other cases it was based on P3HT:PCBM or $\mathrm{P} 3 \mathrm{HT}-\mathrm{co}$-P3AcET:PCBM processed from solution. A larger variation occurred in the application of electron transport-hole blocking and hole transport-electron blocking layers, as well as in electrode materials and structures. Five of the devices were processed on glass and two on flexible PET-substrates. Whereas the flexible devices were protected by barrier sealing including a UV-filter, only some of the devices processed on glass were sealed under glass or stainless steel. Overall, seven distinctively different device architectures were used and large variations in the cell size, its architecture and the fabrication process form the experimental basis for improving the fundamental understanding about various degradation processes and the applicability of complementary characterization methods.

\subsection{Degradation protocols and testing conditions}

The degradation and testing conditions carried out for the different devices have been described in our first publication. ${ }^{2}$

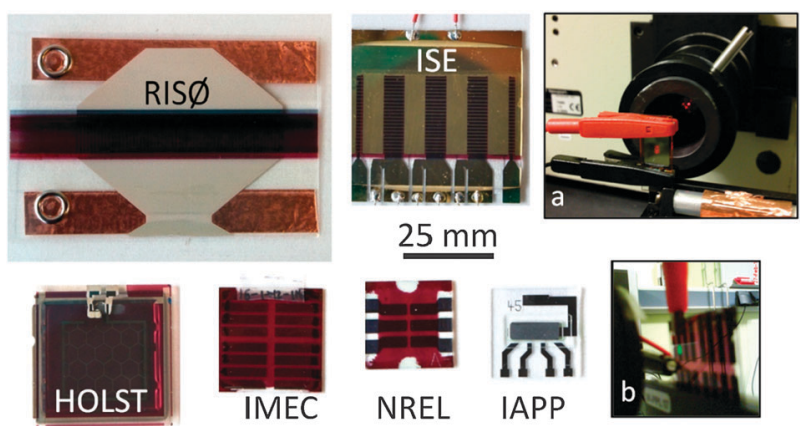

Fig. 1 Solar cell devices from each laboratory at real scale. The illuminated area for the setup at CIN2 with own device (a) and the illuminated area for an IMEC device in the IPCE setup at CIN2 (b). Analyses are carried out in the dark. 
The devices were submitted from the corresponding home laboratory to RISØ-DTU and then to our laboratory, CIN2, for IPCE and $I V$ curve analysis. Devices labelled as 'reference' were analyzed by the home laboratory right after fabrication, at RISØ-DTU and also at CIN2 before any stability tests were carried out. For practical purposes we identify these solar cells as $T_{100}$. Nevertheless, the time that passed between device fabrication and analysis at CIN2 was more than a month, this time lapse should be kept in mind, and will be commented in the corresponding section. Nevertheless, for practical reasons, reference devices analyzed at CIN2 are also labelled $T_{100}$. Once the stability tests were carried out at the RISØ-DTU laboratory, the devices were shipped to CIN2 to carry out the $I V$ curves and the IPCE analyses. In the cases where a substrate comprises several solar cells, i.e. IMEC, NREL, ISE and IAPP, a single solar cell was chosen to carry out the stability test at RISØ-DTU, ${ }^{2}$ but at CIN2 all solar cells within a substrate were analyzed by the IPCE techniques and by $I V$ curves.

\subsection{IPCE analysis}

The devices received at CIN2 were analyzed by IPCE and $I V$ curves within the same time interval. $I V$ curves were recorded at $1000 \mathrm{~W} \mathrm{~m}^{-2}$ in a sun simulator KHS Solar Constant 1200 calibrated with both a pyranometer (Kipp \& Zonen, CM 4) and a solar reference cell from ABET tech (NIST traceable calibration). The $I V$ curves were recorded with a Keithley 2601, applying the Solar_Cell_v4_SP software developed by Mikkel Jørgensen at RISØ-DTU. The IPCE analyses were carried out with a QE/IPCE measurement System from Newport (300 W Xe light source, digital lock in measurement with NIST calibrated detector) at $10 \mathrm{~nm}$ intervals between 300 and $1000 \mathrm{~nm}$. A calibrated photodiode from Hamamatsu (S1227-1010BQ) was also used to calibrate the equipment before each experiment. The results were not corrected for intensity losses due to light absorption and reflection by the glass support and not interference effects were considered. ${ }^{5}$ Analyses were carried out in the dark without light bias.

The main challenge to perform the IPCE analyses was the different dimensions of the solar cells observed between all different devices. Fig. 1 shows the images of all the devices analyzed in this work, and the dimensions for each device. For comparison purposes Fig. 1a shows the IPCE setup showing the dimensions of a device and the irradiated area for a CIN2 device and setup. Fig. $1 \mathrm{~b}$ shows a representation of the irradiated area for an IMEC device. As it can be observed, it was unfeasible to fit the irradiated area of the CIN2 setup to the active area of all the analyzed devices, especially for those devices with similar or smaller active areas than the irradiated beam, like NREL, IMEC and especially for IAPP which has the smallest area of all. The ISE device has front metal electrode grids that can also interfere with the light beam, producing a shadow. These issues can compromise the quantitative IPCE measurement, since irradiating the devices outside the active area results in lower IPCE values. Taking the latter into account, the results presented in the work include the IPCE analysis and also the normalized IPCE spectra. The results were also correlated with the corresponding $I V$ curves for each device analyzed.

\subsection{The in situ IPCE analysis}

The in situ IPCE analysis refers to the analysis of a sample by IPCE at regular periods of time when the testing atmosphere is changed from ambient air to a $\mathrm{N}_{2}$ atmosphere. The method permits us to monitor any changes observed in the solar cell when oxygen is eliminated from the environment. It is also an easy method to identify the materials that are more susceptible to degradation due to the ambient atmosphere. The comparison between the IPCE from each stability test and the in situ IPCE analyses can permit us to distinguish between different processes and to find new peaks not seen in the IPCE spectrum of a freshly prepared device. In the encapsulated devices we can separate information like photolysis (in the absence of oxygen and moisture) and photooxidation due to oxygen and moisture when the device is opened to air. To carry out the in situ IPCE analyses, devices were introduced into a homemade holder designed at CIN2 as shown in Fig. 2. The CIN2's cell holder has been described before for small devices $(5 \mathrm{~cm}$ diameter window). ${ }^{6}$ Briefly, it consists of a two-piece glass reactor with a cooling jacket for temperature control, with a home-designed o-ring sealed cap. It has ports for thermocouple, inlet and outlets for low pressure gas flow, quartz window and cable connections. Due to different solar cell sizes, we modified the described cell holder to accommodate a $15 \mathrm{~cm}$ quartz window, so a variety of solar cells can be analyzed as shown in Fig. 2c (RIS $\varnothing$-DTUs $10 \mathrm{~cm} \times 10 \mathrm{~cm}$ flexible substrate) and Fig. 2d (IMEC's solar cell). The in situ IPCE analysis was carried out on five devices: NREL, IMEC, RISØ-DTU, IAPP and HOLST. Due to the type of encapsulation, the ISE device was not included in these tests. In the case of IAPP and HOLST, the devices are fabricated using glass and encapsulated with lids of glass and stainless steel respectively, using adhesives, so an opening was made on the devices for air from the atmosphere to penetrate into the solar cell. Once the device was placed inside the cell holder, the in situ IPCE test was carried out every few minutes at the same time that $\mathrm{N}_{2}$ was introduced into the cell holder at a constant rate. Thus, IPCE curves were recorded from the transition from ambient

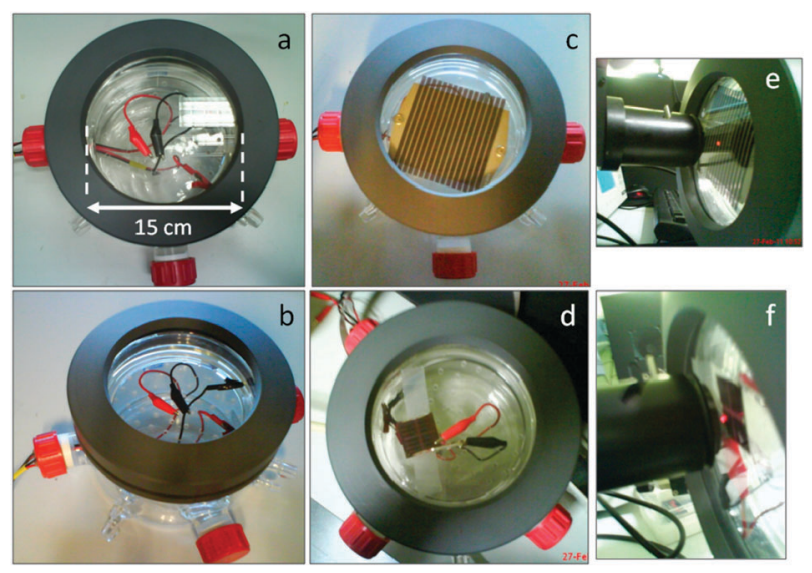

Fig. 2 CIN2's OPV holder with a $15 \mathrm{~cm}$ diameter quartz window used for the in situ IPCE analysis, (a) upper view, (b) side view, (c) holding a RISØ-DTU's solar cell, (d) holding IMEC's solar cell, (e) and (f) RISØ-DTU's and IMEC's solar cells under irradiation respectively. Analyses are carried out in the dark. 
atmosphere to the inert $\mathrm{N}_{2}$. Since our aim is to observe the changes in the IPCE peaks with time, and the methodology ensures that the irradiated area is always the same during the experiment, the graph of the in situ IPCE intensity is presented in some cases in arbitrary units. The comparison of the normalized IPCE spectra obtained in air and under $\mathrm{N}_{2}$ atmosphere gives an indication of the peaks and/or wavelength region affected by the atmosphere.

\section{Results and discussion}

This part is divided into 4 sections. The first section (3.1) includes the general characterization of all devices at $T_{100}$ (reference samples). We describe the normalized IPCE spectra for all samples and identify each peak. Sections 3.2 to 3.4 detail the analysis of each device under different stability tests: accelerated full sun simulation, low level indoor fluorescent lighting and dark storage, depending on the type of encapsulation.

The encapsulated devices were observed to be very reproducible and the area under the curve of the IPCE spectra corresponded well with the $J_{\mathrm{sc}}$ values from the $I V$ curve. The power conversion efficiency (PCE) trend (with a few exceptions) corresponds well with the trend observed for the $J_{\mathrm{sc}}$. This is true for the reference devices and for the first stages of any of the stability tests. Nevertheless, the longer the stability tests the higher the error in the output data, especially for the un-encapsulated devices. The un-encapsulated samples showed high reproducibility problems and erratic response that will be described in the corresponding section. Despite this, the conclusions obtained from these devices were ample. The NREL and IMEC devices are made of several solar cells per substrate which permitted a valuable comparison of their response and reproducibility. In addition, the combination of similar aspects between these un-encapsulated devices (similar materials, device configuration and substrate design) revealed hitherto inaccessible information and degradation mechanisms.

To facilitate the interpretation of the results, each section is independent of others and can be read separately. The reader will be directed to a related section when necessary. To learn about the stability of the OPV devices with two ITO-free alternatives (HOLST and ISE) see Section 3.2. The effect of two different
P3HT polymers (RISØ-P and RISØ-S) is described in Section 3.3. The analysis of the stability under ambient air depending on the two different hole extraction layers PEDOT and $\mathrm{MoO}_{3}$ (NREL and IMEC) is reflected in Section 3.4.

\subsection{General characterization. Reference devices}

Table 1 shows the IPCE peaks found in each of the solar cells analyzed and their assignment (the corresponding IPCE spectra are included in Fig. S1, ESI $\dagger$ ). Devices were measured at $T_{100}$ (used as references) approximately 1 month after the home laboratories shipped the solar cells to RISØ-DTU and to CIN2. The measurements were carried out before any stability test was performed.

All devices, except for IAPP, use similar active layer materials, the P3HT:PCBM blend, so bands corresponding to the P3HT are observed at around $490 \mathrm{~nm}, 520 \mathrm{~nm}$ and $600 \mathrm{~nm}$, as well as for the PCBM between 450 and $600 \mathrm{~nm} .{ }^{24}$ Fig. S1A (see ESI $\dagger$ ) shows the only two un-encapsulated devices: (a) IMEC and (b) NREL, both devices present inverted configuration. These devices show many similarities since their solar cell configuration and substrate designs are very similar: ITO/ZnO/PCBM:P3HT/ $\mathrm{HEL} / \mathrm{Ag}-\mathrm{Al}$, where the only difference is the hole extraction layer (HEL) which is PEDOT:PSS in the case of NREL (Fig. S1Ab, ESI $\dagger$ ), and $\mathrm{MoO}_{3}$ in the case of IMEC (Fig. S1Aa, ESI $\dagger$ ). The resulting IPCE graphs show very similar shape, with two main differences corresponding to the UV region below $400 \mathrm{~nm}$ and a peak at $430 \mathrm{~nm}$ that appears in the NREL device. In the case of the IMEC device the UV region below $400 \mathrm{~nm}$ is wider than for the NREL solar cell, due to the absorption of both, the electron extraction layer (EEL) made of $\mathrm{ZnO}^{17,18}$ and the hole extraction layer (HEL) made of $\mathrm{MoO}_{3} \cdot{ }^{7-10}$ In the case of NREL only the peak that corresponds to $\mathrm{ZnO}$ is observed at $380 \mathrm{~nm}$. The PEDOT:PSS layer is observed indirectly by a peak at $425-440 \mathrm{~nm}$ that has been attributed to the interaction between PEDOT:PSS and the metal electrode Ag. ${ }^{21-23}$ The formation of a chemical bond between the $\mathrm{Ag}$ and the PEDOT:PSS is possible due to the attraction of the S-atom of PEDOT towards some metals like $\mathrm{Ag}$ and $\mathrm{Au} .{ }^{25} \mathrm{~A}$ nanocomposite of the type [PEDOT:PSS.Ag] is known to absorb in the UV-Vis at around $\sim 420-450 \mathrm{~nm}^{21-23}$ This peak is also present in the IPCE spectra of the devices where the PEDOT:PSS

Table 1 Assignment of the peaks observed by IPCE analysis for all the OPV devices analyzed in this work. The X in brackets indicates that a peak is expected but not clearly seen

\begin{tabular}{|c|c|c|c|c|c|c|c|c|c|}
\hline Peak (nm) & Assignment & IAPP & ISE & HOLST & RISØ-P & RISØ-S & NREL & IMEC & Ref. \\
\hline 340 & $\mathrm{MoO}_{3}$ & & & & & & & $\mathrm{X}$ & $7-10$ \\
\hline 340 & $\mathrm{ZnPc}$ & $\mathrm{X}$ & & & & & & & $11-14$ \\
\hline 366 & $\mathrm{Cr} / \mathrm{Al}$ & & $\mathrm{X}$ & & & & & & 15,16 \\
\hline 375 & $\mathrm{ZnO}$ & & $\mathrm{X}$ & & $X$ & $\mathrm{X}$ & $\mathrm{X}$ & $\mathrm{X}$ & 17,18 \\
\hline 380 & $\mathrm{C}_{60}$ & $\mathrm{X}$ & & & & & & & 19,20 \\
\hline $425-440$ & [PEDOT:PSS·Ag] & & & $\mathrm{X}$ & $(\mathrm{X})$ & $(\mathrm{X})$ & $\mathrm{X}$ & & $21-23$ \\
\hline 440 & [PEDOT:PSS·Au] & & $\mathrm{X}$ & & & & & & $21-23$ \\
\hline 450 & PCBM & & $\mathrm{X}$ & $\mathrm{X}$ & $\mathrm{X}$ & $\mathrm{X}$ & $\mathrm{X}$ & $\mathrm{X}$ & 24 \\
\hline 450 & $\mathrm{C}_{60}$ & $\mathrm{X}$ & & & & & & & 19,20 \\
\hline 490 & P3HT & & $\mathrm{X}$ & $\mathrm{X}$ & $\mathrm{X}$ & & $\mathrm{X}$ & $X$ & 24 \\
\hline 520 & P3HT & & $\mathrm{X}$ & $\mathrm{X}$ & $\mathrm{X}$ & & $\mathrm{X}$ & $\mathrm{X}$ & 24 \\
\hline 600 & P3HT & & $\mathrm{X}$ & $\mathrm{X}$ & $\mathrm{X}$ & & $\mathrm{X}$ & $\mathrm{X}$ & 24 \\
\hline 600 & PCBM & & $\mathrm{X}$ & $\mathrm{X}$ & $\mathrm{X}$ & $\mathrm{X}$ & $\mathrm{X}$ & $\mathrm{X}$ & 24 \\
\hline 635 & $\mathrm{ZnPc}$ & $\mathrm{X}$ & & & & & & & 11,14 \\
\hline 680 & $\mathrm{ZnPc}$ & $\mathrm{X}$ & & & & & & & 11,14 \\
\hline
\end{tabular}


is in direct contact with a Au or Ag metal electrode like in the ISE, HOLST and NREL devices. The peak should also be observed in the RISØ-DTU devices but the shape of the RISØ-DTU IPCE spectra could be hiding the peak (the peak value has been added in brackets in Table 1).

Fig. S1B (ESI $\dagger$ ) shows the two RISØ-DTU devices. The main difference between them is the polymer applied. The RISØ-P applies the P3HT polymer, while RISØ-S uses a functionalized copolymer (poly-(3-hexylthiophene)-co-(3-(2acetyloxyethyl)thiophene)), the molecular formulae are shown in the inset of Fig. S1B (ESI $\dagger$ ). Both IPCE graphs are very similar in shape with a slight blue shift observed for the RISØ-S device. The absence of peaks in both RISØ-DTU devices below $400 \mathrm{~nm}$ is due to the presence of a UV filter that cuts light absorption below $400 \mathrm{~nm}$ and, thus, eliminates the peak of the $\mathrm{ZnO}$ electron extraction layer (EEL). Fig. S1C $(\mathrm{ESI} \dagger)$ shows the inverted solar cell from the ISE laboratory, this IPCE is very similar to the above described devices. In this case, the ITO electrode has been replaced by a transparent thin layer made of PEDOT:PSS with a Au grid. An opaque $\mathrm{Cr} / \mathrm{Al} / \mathrm{Cr}$ triple layer acts as an electron collector. The peak below $400 \mathrm{~nm}$ that appears for the ISE device is probably due to the absorption of the $\mathrm{Cr} / \mathrm{Al} / \mathrm{Cr}$ electrode since $\mathrm{Al}_{x} \mathrm{Cr}_{y}$ catalysts have been reported to absorb at around $366 \mathrm{~nm} .^{15,16}$ The slight shoulder at about $450 \mathrm{~nm}$ can be attributed to the [PEDOT:PSS·Au] interaction which has been reported to absorb at slightly longer wavelengths than the [PEDOT:PSS·Ag] nanocomposite. ${ }^{21-23}$ Fig. S1D (ESI $\dagger$ ) compares the four IPCE spectra of the inverted OPVs of this work: (a) RISØ-P, (b) NREL, (c) ISE and (d) IMEC. The NREL and IMEC devices are un-encapsulated, while RIS $\varnothing-P$ and ISE are semiencapsulated and encapsulated devices respectively. We consider the RISØ-DTU devices to be semi-encapsulated since oxygen and moisture can penetrate the type of plastic encapsulation used (PET). It is interesting to observe in Fig. S1D (ESI $\dagger$ ) that the maximum IPCE peaks of the four devices are located at different wavelengths, from $470-500 \mathrm{~nm}$ for the encapsulated (ISE) and the semi-encapsulated device (RISØ-P), and about $560 \mathrm{~nm}$ for the un-encapsulated devices (NREL and IMEC). The red shift observed for the maximum peak for the devices is attributed to the interaction of organic semiconductors, P3HT and PCBM, with oxygen from air. ${ }^{26-31}$ The HOLST device is an ITO-free organic solar cell with a normal configuration and presents the typical features of an OPV solar cell as already described (Fig. S1E, ESI $\dagger$ ). The HEL is a PEDOT:PSS layer in direct contact with the Ag grid electrode thus showing the presence of a peak at $430 \mathrm{~nm}$. Finally, the IAPP device (Fig. S1F, ESI $\dagger$ ) is a small molecule OPV made by vacuum processing. The IPCE spectra of the IAPP device consist of five clearly distinguished peaks, three for zinc phthalocyanine $(\mathrm{ZnPc})$ and two for the $\mathrm{C}_{60}$ molecule.

\subsection{Encapsulated devices: IAPP, ISE and HOLST}

3.2.1. IAPP: ITO/BF-DPB: $\mathrm{C}_{60} / \mathrm{ZnPc}_{\mathbf{6}} \mathrm{C}_{60} / \mathrm{BPhen} / \mathrm{Al}$. The small molecule organic solar cell IAPP devices, made of vacuum processed $\mathrm{ZnPc}: \mathrm{C}_{60}$ bulk heterojunction, resulted in very stable devices as already reported. ${ }^{2,3}$ The five peaks in the
IPCE spectra of the IAPP sample correspond to the $\mathrm{ZnPc}$ at $340 \mathrm{~nm}, 630-640 \mathrm{~nm}$ and $680-700 \mathrm{~nm},{ }^{11-14}$ and to the $C_{60}$ molecule at $380 \mathrm{~nm}$ and $460 \mathrm{~nm} .{ }^{19,20}$ The $\mathrm{ZnPc}$ peaks are in good correspondence with the absorption bands observed in the UV-Vis absorption spectra, called the B (or Soret) band around $300-400 \mathrm{~nm}$ in the $\mathrm{UV}$ region, and the $\mathrm{Q}$ band in the visible region between 400 and $800 \mathrm{~nm} \cdot{ }^{14,32}$ The devices were analyzed by IPCE as encapsulated and un-encapsulated devices. For comparison purposes, the corresponding $I V$ curve was also recorded right before IPCE analyses. The encapsulated devices were analyzed at $T_{90}$ for three different stability tests (dark storage, low intensity fluorescent light and full sun). The latter represents more than $1700 \mathrm{~h}$ of testing under each condition as detailed in Table 2. Some untreated devices $\left(T_{100}\right)$ were opened to air by breaking the seal, by means of a hole made through the glass, and were used for the in situ IPCE analysis in a $\mathrm{N}_{2}$ atmosphere. Results revealed clear differences under encapsulation conditions and in the presence of ambient air.

Comparison of IPCE results at $T_{100}$ at the home laboratory. All devices were analyzed at $T_{100}$ before shipping the devices back to RISØ-DTU for stability tests. It is important to notice that we call $T_{100}$ the devices received in our laboratory at CIN2, but more than a month had passed between the fabrication of the devices at the IAPP home laboratory, and the arrival to CIN2. The IAPP devices showed differences between the IPCE analysis obtained at CIN2 and those measured at the home laboratory (Fig. 3). Although the IPCE spectra were very similar, differences within the wavelength range below $550 \mathrm{~nm}$ were clearly observed. This wavelength region encompasses one peak of the $\mathrm{ZnPc}$ at $340 \mathrm{~nm}$, and two peaks that correspond to the $\mathrm{C}_{60}$ molecule at $380 \mathrm{~nm}$ and $460 \mathrm{~nm}$. In the case of the IAPP results, a single peak at about $350 \mathrm{~nm}$ is observed instead of the two lower-intensity peaks at $340 \mathrm{~nm}$ and $380 \mathrm{~nm}$ observed for the CIN2 analyses. The one single peak for the IAPP devices clearly overlaps with the peak at $380 \mathrm{~nm}$, since some spectra show the presence of a shoulder at $380 \mathrm{~nm}$ (Fig. 3). The difference in this peak observed between the two laboratories can be explained by the Davydov splitting which occurs in the B or Soret band at $340 \mathrm{~nm}$ of the ZnPc. ${ }^{33}$ This splitting is attributed to the presence of more than one (interacting) equivalent molecular entity in the unit cell. The effect has been observed on phthalocyanines and has been attributed to many effects, like the metal atom, ${ }^{33}$ temperature, ${ }^{14}$ the presence of oxygen, ${ }^{34}$ or due to light irradiation. ${ }^{32,35}$ For example, El-Nahass et al. reported the splitting of the $\mathrm{ZnPc}$ absorption peak at $335 \mathrm{~nm}$ into two peaks at $336 \mathrm{~nm}$ and $364 \mathrm{~nm}$. The splitting was also accompanied by a slight shift of the resulting doublet towards the red and the decrease in the

Table 2 Photovoltaic values for encapsulated IAPP devices analyzed at $T_{90}$ by different stability tests

\begin{tabular}{lllllll}
\hline Device & $\begin{array}{l}\text { Test } \\
\text { duration/h }\end{array}$ & $\begin{array}{l}V_{\mathrm{oc}} \\
(\mathrm{V})\end{array}$ & $\begin{array}{l}I_{\mathrm{sc}} \\
(\mathrm{mA})\end{array}$ & $\begin{array}{l}J_{\mathrm{sc}} \\
\left(\mathrm{mA} \mathrm{cm} \mathrm{cm}^{-2}\right)\end{array}$ & $\begin{array}{l}\mathrm{FF} \\
(\%)\end{array}$ & $\begin{array}{l}\text { PCE } \\
(\%)\end{array}$ \\
\hline IAPP dark & 1745 & 0.48 & -0.52 & -8.27 & 54.28 & 2.16 \\
IAPP fluorescent & 1751 & 0.43 & -0.54 & -8.58 & 54.77 & 2.05 \\
IAPP full sun & 1823 & 0.49 & -0.53 & -8.40 & 51.79 & 2.16 \\
\hline
\end{tabular}



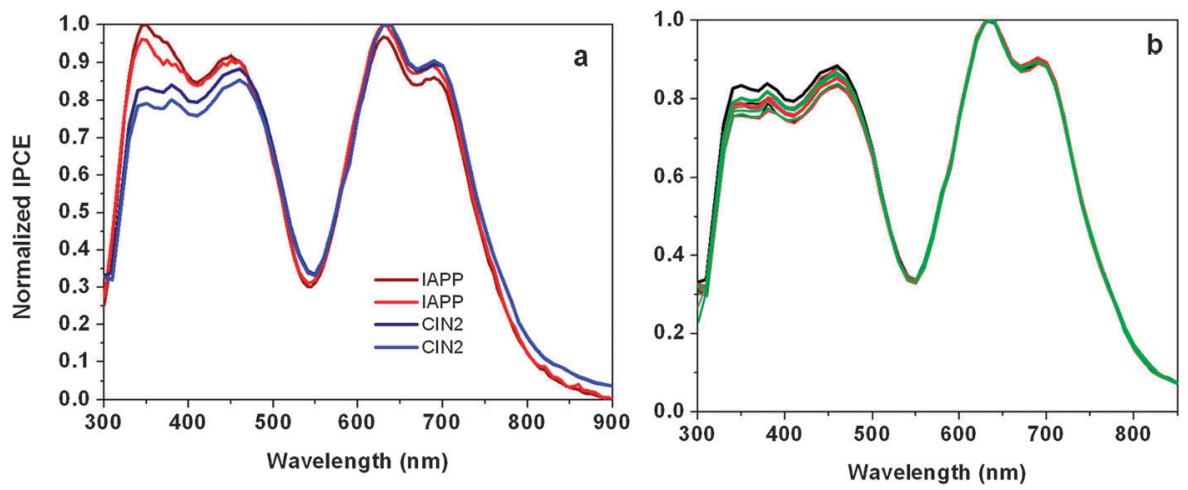

Fig. 3 Normalized IPCE spectra for the IAPP reference devices at $T_{100}$. (a) Comparison between two devices measured at the IAPP home laboratory and at CIN2 (a), and (b) comparison of all reference solar cells measured at CIN2. The spectra are normalized to the maximum peak.

intensity for the splitted peaks below $400 \mathrm{~nm} .^{33}$ The latter agrees with the differences observed for the IPCE spectra analyzed by both laboratories. Moreover, the variation between IPCE spectra observed by IAPP could encompass devices with single peaks and double (or splitted) peaks. The latter could probably be due to changes in the materials occurring in the time period between initial fabrication of the devices at IAPP and shipment to CIN2. It should be stressed that those changes do not compromise the power conversion efficiency of the devices and also that a more elaborate set of experiments and analysis will be needed in order to clearly attribute these changes to a specific mechanism.

Effect of the type of light irradiation. The $I V$ curves corresponding to the encapsulated devices analyzed under the three different stability tests at $T_{90}$ (after more than $1700 \mathrm{~h}$ of testing) are shown in Fig. 4 and the corresponding photovoltaic values are detailed in Table 2 .

The photovoltaic response in all three cases is almost identical, with PCEs between 2 and $2.16 \%$. Differences between the devices can only be observed by comparison of the IPCE spectra obtained from the three different stability tests (Fig. 4). The most remarkable change is observed in the peak at $378 \mathrm{~nm}$ that increases with the increasing irradiation dose when moving from the different stability tests (a reference cell at $T_{100}$ is also included for comparison). The reproducibility within the 4 devices of each substrate is also very consistent for each test. Peaks at $340 \mathrm{~nm}, 630 \mathrm{~nm}$ and $670 \mathrm{~nm}$ of the $\mathrm{ZnPc}$ do not show any important changes, whereas the strong increase in the IPCE peak at $378 \mathrm{~nm}$, together with the slight decrease in the peak at $450 \mathrm{~nm}$, corresponds to the absorption of the $\mathrm{C}_{60}$ molecule. These results agree with the photosensitivity of $\mathrm{C}_{60}$ observed for similar devices and reported earlier. ${ }^{11}$ Song et al. have also reported on the degradation of carefully encapsulated devices, where authors observed the degradation of $\mathrm{C}_{60}$ and stated that not the effect of oxygen or water but some other factor is responsible for this response. ${ }^{36}$ The possibility that the effect is due to the Davydov splitting is negligible since it would mean that the Soret band at $\sim 378 \mathrm{~nm}$ (in the full sun spectra) should split into $340 \mathrm{~nm}$ and $380 \mathrm{~nm}$ peaks (observed in the dark and reference spectra respectively) without any red shifting of the bands. The latter is different enough as compared to the above-mentioned work ${ }^{33}$ and rules out the Davydov splitting effect of the peak. Thus, we attribute the changes observed in the peak at $\sim 378 \mathrm{~nm}$, and the slight reduction of the peak at $450 \mathrm{~nm}$, to a photo-induced effect on the $\mathrm{C}_{60}$ molecule. The latter is also in good agreement with the already published report on the degradation of $\mathrm{C}_{60}$, by cage fragmentation, induced by light. ${ }^{37}$

All these results indicate that any degradation in the IAPP devices could be initially affected by a photo-induced effect on the $\mathrm{C}_{60}$ molecule. Nevertheless, these changes have a negligible effect on the overall solar cell efficiency at this stage of the
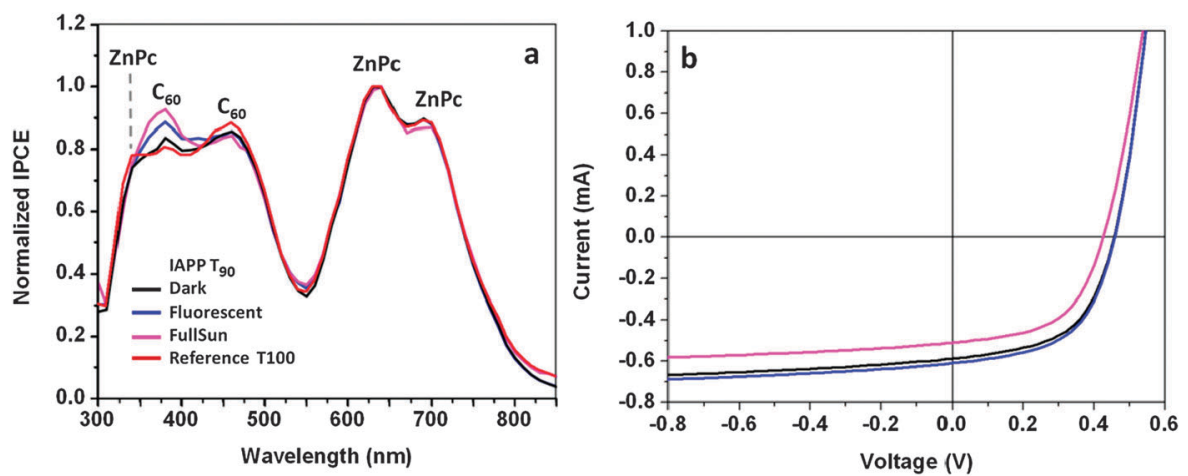

Fig. 4 Normalized IPCE spectra (a) and $I V$ curves (b) of the IAPP solar cells analyzed by different stability tests at $T_{90}$. A reference cell ( $\left.T_{100}\right)$ has been included for comparison. 
tests $\left(T_{90}\right)$ as the efficiency is almost unchanged after more than $1700 \mathrm{~h}$ of aging.

In situ IPCE analysis: effect of ambient air. The in situ IPCE analyses, carried out for an un-encapsulated device, reveal the interaction of the solar cell materials with the atmosphere (oxygen, moisture) at initial stages. Changes observed in the IPCE correspond to the same irradiation area of the same device, and are obtained when the device is opened to air and every few minutes after $\mathrm{N}_{2}$ gas is introduced into the cell holder (Fig. 5). The IPCE spectra obtained after the device was opened to the ambient atmosphere (black line, Fig. 5a) decrease steadily with time after the $\mathrm{N}_{2}$ gas is introduced. The re-introduction of air provokes a reversible effect and the intensity of the whole IPCE spectra is observed to increase (pink dotted line, Fig. 5a). Comparison of the normalized IPCE spectra (Fig. 5b and c) shows clear differences between
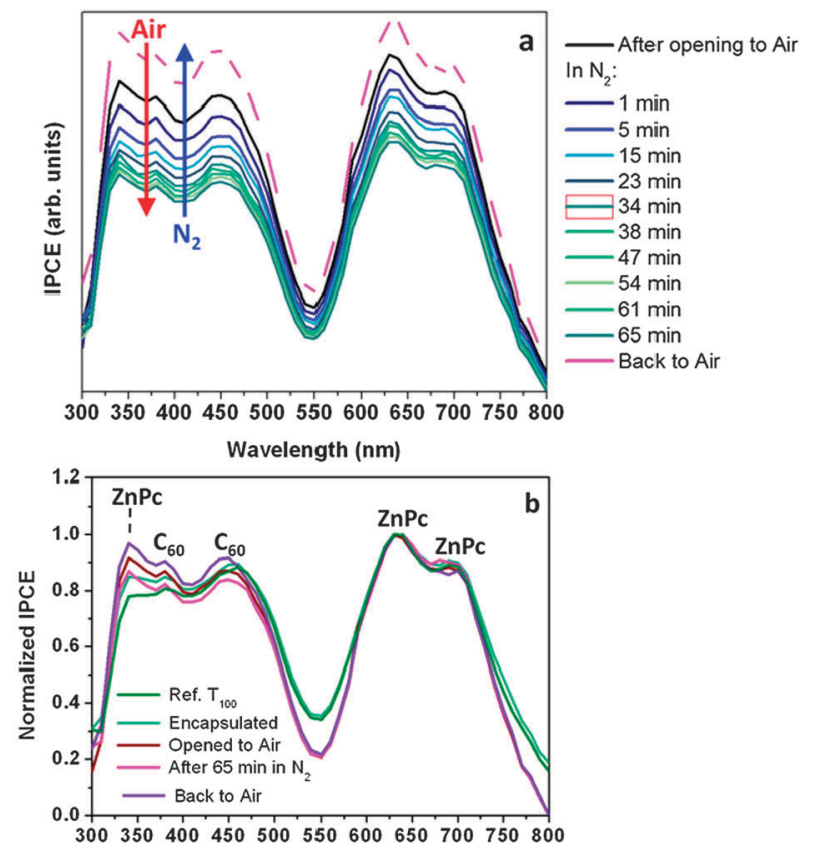

Wavelength $(\mathrm{nm})$

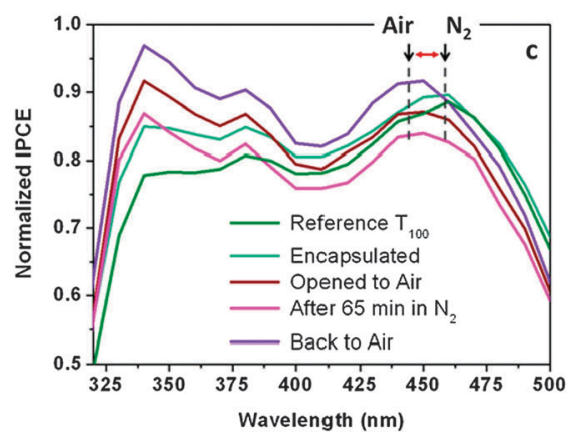

Fig. 5 Un-encapsulated device IAPP 13_2: (a) In situ IPCE analysis taken from ambient atmosphere to $\mathrm{N}_{2}$, (b) the normalized IPCE spectra, and (c) IPCE spectra in (b) at a wavelength range between $320 \mathrm{~nm}$ and $500 \mathrm{~nm}$. The analysis was carried out on the device IAPP 13 2 after a hole was made through the glass that allows air to penetrate the device. The atmosphere was then changed from air to $\mathrm{N}_{2}$ for several minutes. The reference device corresponds to the 10-3-IAPP encapsulated device at $T_{100}$. the encapsulated device and the one that was opened to air: (i) different peak intensity, (ii) increase of the Soret peak of the $\mathrm{ZnPc}$ at $340 \mathrm{~nm}$, and (iii) a blue shift of the peak around $460 \mathrm{~nm}$ which moves to $440-450 \mathrm{~nm}$ in air (see also Table 3 ). The increase of the overall IPCE spectra (Fig. 5a) in air is not surprising, it is well documented that molecular oxygen largely determines the properties of many organic semiconductors, among them $\mathrm{ZnPc}^{34,38}$ and $\mathrm{C}_{60} \cdot{ }^{26}$ Oxygen dopes the $\mathrm{ZnPc}$ by taking an electron from the phthalocyanines, becoming p-type. The latter increases the current density and the photovoltaic properties of solar cells ${ }^{30,34,38}$ due to the formation of a charge transfer complex (CTC). ${ }^{29}$ Fig. $5 \mathrm{c}$ shows how the intensity of the peak at $340 \mathrm{~nm}$ is lower in the absence of oxygen (encapsulated and reference) and increases when air is in contact with the materials. The latter also agrees with the blue shift of the peak at $460 \mathrm{~nm}$, which is also an indication of the formation of a CTC between the organic semiconductor and oxygen from the air. An interesting observation is that once the device is opened to air the blue shift of the peak at $450 \mathrm{~nm}$ is no longer reversible (not even after 65 min under $\mathrm{N}_{2}$ ), an indication of the irreversible sensitivity (photobleaching) of the $\mathrm{ZnPc}$ to air as already reported. ${ }^{39}$ In the case of the $\mathrm{C}_{60}$, oxygen is known to diffuse into the bulk of $\mathrm{C}_{60}$, modifying the electronic properties of the material. ${ }^{26}$ Under long exposure to ambient air, the face centered cubic (fcc) $\mathrm{C}_{60}$ transforms into amorphous carbon-oxygen compounds, and the icosahedral $\mathrm{C}_{60}$ molecular structure is destroyed. ${ }^{31}$ The complete degradation of IAPP devices under ambient air results in a decrease in intensity of the entire IPCE spectrum, as observed in Fig. S2 (ESI $\dagger$ ) for a device analyzed at $T_{14}$. The reduction in intensity of the whole spectra during aging has also been reported by Hermenau et al. $^{40}$

\subsubsection{HOLST: Glass/Ag/PEDOT:PSS/P3HT:PCBM/LiF/}

Al. The HOLST device is an ITO-free normal configuration OPV. Instead of ITO, the hole extracting electrode is made of a Ag grid and a highly conductive PEDOT:PSS hybrid front electrode, and a $\mathrm{LiF} / \mathrm{Al}$ as the electron extracting layers. The device is encapsulated between the glass substrate and a stainless steel plate.

The HOLST devices were observed to be stable under dark storage and low-intensity fluorescent light, owing to their glass-type encapsulation. The relation between PCE and $J_{\mathrm{sc}}$ (from $I V$ curve and from IPCE analysis) followed the same trend for all the reference devices, as well as for each stability test. The comparison between reference devices and the dark storage analysis shows two main features (not shown): (a) a red shift is observed for the peak at $420 \mathrm{~nm}$ that moves towards $460 \mathrm{~nm}$, and (b) the sharpening of the peak at $600 \mathrm{~nm}$. The peak at $420 \mathrm{~nm}$ is associated with the reaction between $\mathrm{Ag}$ and PEDOT:PSS and the red shift indicates the increase of the reaction over time..$^{21-23}$ These results indicate that even under encapsulation, in the absence of oxygen and moisture, the solar cell materials interact with each other, degrading the device performance. The shifting of the peak at $420 \mathrm{~nm}$ towards $460 \mathrm{~nm}$ indicates that the interaction of the Ag-PEDOT:PSS layer is almost spontaneous (as reported in diverse documents) and does not require the presence of ambient atmosphere to initiate the degradation of the Ag electrode. 
Table 3 IPCE peaks observed for the IAPP device under encapsulated conditions and after the device was exposed to ambient atmosphere

\begin{tabular}{lllll}
\hline & Encapsulated & In air & In air & Assignment \\
\hline ZnPc (Soret band) & 340 & 340 & Increases & CTC formation with oxygen \\
$\mathrm{C}_{60}$ & 380 & 380 & & \\
$\mathrm{C}_{60}$ & 460 & $440-450$ & Irreversible blue shift & CTC formation with oxygen and degradation \\
$\mathrm{ZnPc}(\mathrm{Q}$ band) & $630-640$ & 635 & & \\
$\mathrm{ZnPc}(\mathrm{Q}$ band) & $680-700$ & $690-700$ & Decreases & Irreversible degradation of ZnPC \\
\hline
\end{tabular}
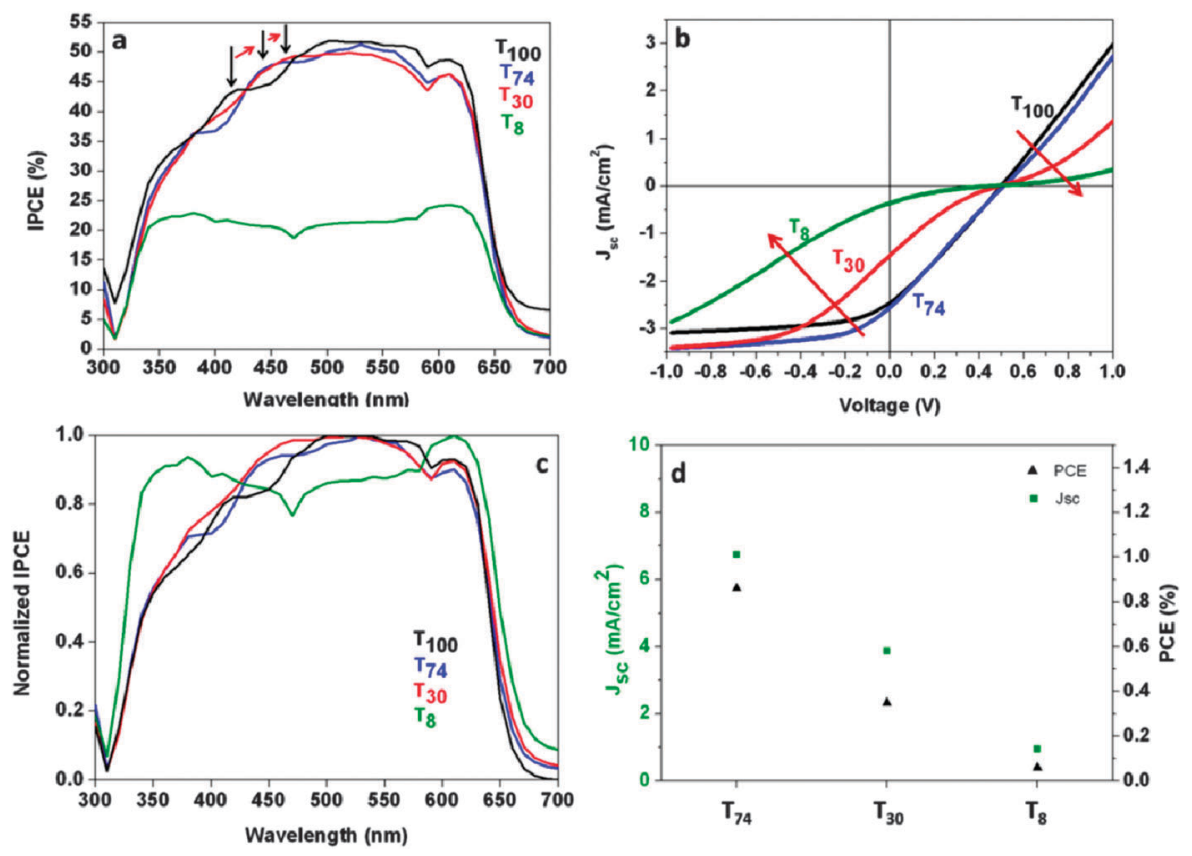

Fig. 6 Normalized IPCE spectra and the corresponding $I V$ curves for the HOLST solar cell after the full sun stability test at $T_{74}, T_{30}$ and $T_{8}$. A reference cell $\left(T_{100}\right)$ was included for comparison. (a) IPCE analysis, (b) $I V$ curves, (c) normalized ICPE graphs and (d) $J_{\text {sc }}$ and PCE at different $T_{x}$.

The results of the full sun stability test are shown in Fig. 6. The graphs correspond to the IPCE and the $I V$ curves of the HOLST devices after the test at $T_{74}, T_{30}$ and $T_{8}$. The degradation of the devices followed by the $I V$ curves indicates a degradation path which corresponds to some features of the IPCE spectra: at $T_{74}$, the IPCE spectra presents a red shift of the peak at $420 \mathrm{~nm}$ towards the $440 \mathrm{~nm}$ as compared to the reference devices (see arrows in Fig. 6a). At $T_{30}$ the shift of the peak at $440 \mathrm{~nm}$ continues until reaching $460 \mathrm{~nm}$. We have attributed the shift of this peak to the interaction of Ag with the PEDOT:PSS layer ${ }^{21-23}$ or the P3HT layer. ${ }^{41}$ The latter can induce the slow but steady degradation of the photovoltaic response of the device by the penetration of $\mathrm{Ag}$ into the PEDOT:PSS layer and the oxidation of the Ag metal electrode over time. The oxidation of the $\mathrm{LiF} / \mathrm{Al}$ electrode is also a possibility which can affect device stability. Nevertheless, the $\mathrm{LiF}$ absorbs at wavelengths above $1000 \mathrm{~nm}$ and it cannot be detected by our methodology. The oxidation of the Al electrode over time is more apparent since the absorption of $\mathrm{Al}$ can be observed at wavelengths below $400 \mathrm{~nm} .{ }^{16}$ In Fig. $6 \mathrm{a}$ and c there is a shoulder at around $350 \mathrm{~nm}$ that decreases with degradation time and could be attributed to this phenomenon. Moreover, a decrease in intensity of the IPCE graph at the spectral range between 500 and $600 \mathrm{~nm}$ that corresponds to the P3HT is observed in Fig. 6a and c, an indication of its degradation over time. Finally, at $T_{8}$ the drastic decrease in the IPCE intensity
(Fig. 6a and c) is in agreement with the complete degradation of the solar cell and the decrease of the photovoltaic properties of the device observed in the $I V$ curve (Fig. 6c).

In situ IPCE analysis: from ambient atmosphere to $\mathrm{N}_{2}$. The HOLST device was analyzed by the in situ IPCE analysis. For this purpose, the glass-seal of the encapsulated device was broken by making a hole through the glass. The device was then placed into a cell holder, as described in the experimental section, and the IPCE analyses were carried out while the atmosphere was changed from air to $\mathrm{N}_{2}$.

Fig. 7 shows the response of the IPCE analyses and the corresponding normalized graphs of the device under encapsulation conditions and after it was opened to air. No clear differences in the IPCE spectral shape were observed after the device was opened to ambient atmosphere, even after $24 \mathrm{~h}$ in air the device showed nice stability. The main changes were observed after $48 \mathrm{~h}$ in ambient air, especially for the peak at $400 \mathrm{~nm}$, that shiffted towards red $(430 \mathrm{~nm})$ accompanied by the increase of the peak at $600 \mathrm{~nm}$. The formation of a new peak at $430 \mathrm{~nm}$ has been attributed to the reaction of the PEDOT:PSS layer with the Ag electrode as detailed before (see also Table 1). ${ }^{21-23}$ The increase of the peak at $600 \mathrm{~nm}$, or the decrease in the intensity of the maximum peak at $500 \mathrm{~nm}$ is related to the degradation of the P3HT polymer. The device was completely degraded after one week under ambient air. 

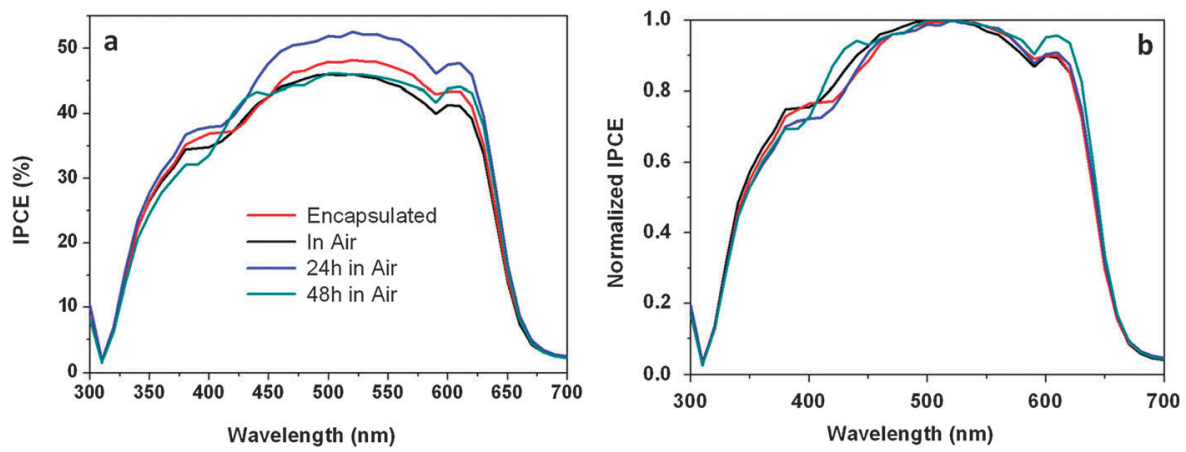

Fig. 7 IPCE spectra (a) and the normalized IPCE graphs (b) obtained for a HOLST device before and after the seal was broken to permit the introduction of the ambient air into the device.
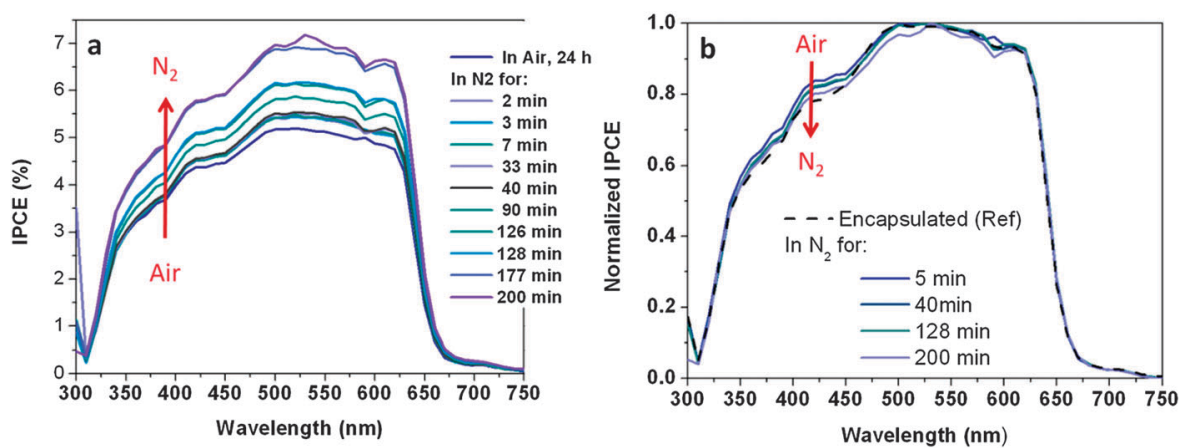

Fig. 8 In situ IPCE spectra of a HOLST device (a) and the normalized IPCE spectra (b). The IPCE spectra in (a) indicate an increase in the IPCE spectra with time, the normalized spectra (b) show a decrease in the peaks with time.

After being opened to ambient air, the device was analyzed by the in situ IPCE technique (Fig. 8). In general, the intensity of the IPCE spectra increases when the device is transferred from ambient atmosphere to $\mathrm{N}_{2}$ (Fig. 8a). The HOLST device is the only one of all the analyzed in this collaborative work that showed an increase in the IPCE intensity when analyzed under a $\mathrm{N}_{2}$ atmosphere, all other devices showed a decrease in the intensity of the peaks. The increase or decrease of the IPCE intensity could in principle be attributed to the degradation or enhancement of the photovoltaic properties of the device, especially $J_{\mathrm{sc}}$. Nevertheless, previous in situ IPCE studies carried out on hybrid solar cells applying different solar cell materials demonstrate that the response can be dependent on a wide variety of factors. ${ }^{6}$ In the mentioned example, the different crystalline structures of the oxide layer were observed to be the reason behind the changes (increase or decrease) in the intensity of the IPCE spectra over time. In addition, the response was only observed in the initial stages of the analysis (up to $2 \mathrm{~h}$ ), after which all samples stabilized at a certain $J_{\text {sc }}$ (and IPCE values). An indication that the response follows complex mechanisms, thus it is not possible at this stage to explain this response without further experimental work. In Fig. 8b the normalized IPCE spectra reveal that the main peaks affected by the atmosphere are those located in the region below $450 \mathrm{~nm}$. The whole region decreases in intensity with time, resembling the reference IPCE spectra of the encapsulated device $\left(T_{100}\right)$. We have related the region below $450 \mathrm{~nm}$ to the $\mathrm{Al}$ absorption at $380 \mathrm{~nm}$ and to the Ag-PEDOT:PSS peak.

The conclusion with respect to the HOLST device its good stability towards dark storage, low intensity fluorescent light and also to ambient atmosphere but in the latter case only in the first hours of analysis. The device shows some degradation after $48 \mathrm{~h}$ in ambient atmosphere and is completely destroyed after 1 month in air.

3.2.3. ISE: Glass/Cr/Al/Cr/P3HT:PCBM/PEDOT/Au/glass. The glass-encapsulated ISE device is an inverted OPV based on the P3HT:PCBM active layer. A PEDOT:PSS layer and $\mathrm{Au}$ grid are used as the transparent hole extraction layer and current collector respectively. $\mathrm{A} \mathrm{Cr} / \mathrm{Al} / \mathrm{Cr}$ electrode is used as the opaque back electrode. Gold electrodes, applied as current collectors, are made on both sides of the device in the form of thin fingers. Due to the type of encapsulation, the ISE device was not analyzed by the in situ IPCE technique.

The ISE device presented clear changes over time when analyzed under full sun. Fig. 9 shows the $I V$ curves and the normalized IPCE analysis for the full sun stability test at different aging time. The wavelength region below $450 \mathrm{~nm}$ is clearly modified during the stability test, probably due to degradation of the $\mathrm{Cr}-\mathrm{Al}-\mathrm{Cr}$ and the $\mathrm{Au}$ electrodes. Since metals like $\mathrm{Ag}, \mathrm{Cu}$ and $\mathrm{Au}$ are known to be attracted by the S-atom of polymers like P3HT and PEDOT, it is possible that the interface layer $\mathrm{Cr}-\mathrm{Al}-\mathrm{Cr} / \mathrm{P} 3 \mathrm{HT}$ reacts in a similar way, as well as the hole extraction layer Au/PEDOT:PSS. In the first case, the peak that can be seen clearly at $360 \mathrm{~nm}$ for the reference device (green line) and attributed to the $\mathrm{Cr} / \mathrm{Al} / \mathrm{Cr}$ electrode increases and disappears over time. In the case of the [PEDOT:PSS·Au] the shoulder at $450 \mathrm{~nm}$ observed for the reference electrode (green line) is maintained over time but is undistinguishable after several hours under full sun light 

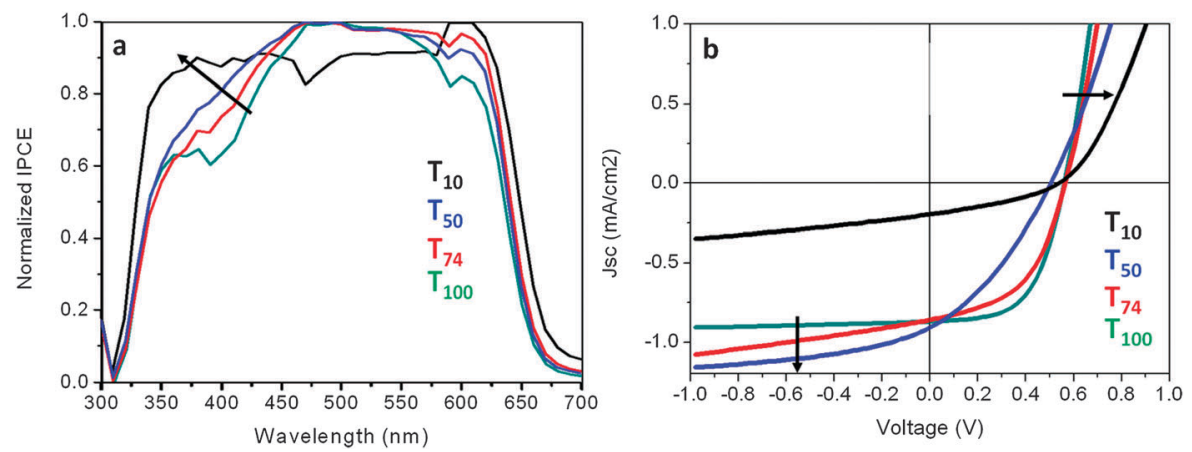

Fig. 9 Normalized IPCE spectra (a) and $I V$ curves (b) for the ISE solar cell after the full sun stability test at different aging time, $T_{100}, T_{74}, T_{50}$ and $T_{10}$.

(due to overlapping with the rest of the IPCE graph). These results indicate that the degradation of the device could be initiated at the electrodes, yet the photovoltaic properties of the device are maintained until $T_{10}$ where a drastic drop of the properties, especially $J_{\text {sc }}$, is observed (Fig. 9b).

\subsection{Semi-encapsulated devices: RISØ-S and RISØ-P}

3.3.1. RISØ-DTU: UV filter/PET/ITO/ZnO/polymer:PCBM/ PEDOT:PSS/Ag/PET. The RISØ-DTU devices are solutionprocessing flexible OPV with an inverted geometry. The main difference between these two devices is the polymers applied for their fabrication, RISØ-P applies the typical P3HT polymer, and the RISØ-S a functionalized copolymer, poly-(3-hexylthiophene)-co-(3-(2-acetyloxyethyl)thiophene) (P3HT-co-P3Ac). The devices also have a thin layer of a $\mathrm{SiO}_{2}$-based polymer film which is used as an external UV filter for the device. Due to the similarity of the devices, this section compares the response of both devices under similar conditions and stabilization tests.
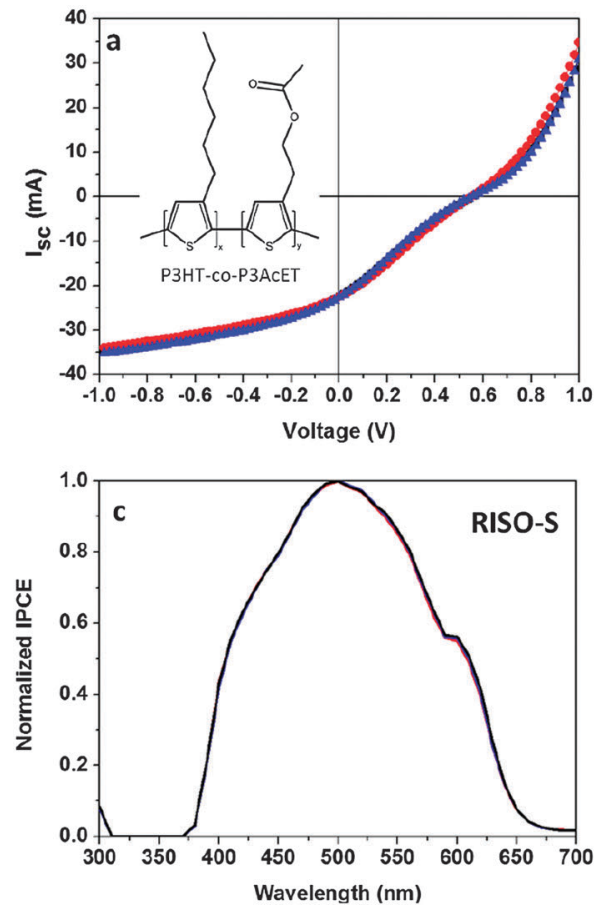

The initial observation on the RISØ-DTU devices is the low power conversion efficiencies found for the reference devices when arrived at CIN2. PCE values between 1.59 and $1.82 \%$ were measured at the RISØ-DTU home laboratory. By the time the devices arrived at CIN2 almost a month had passed and the PCE were observed to be more than $50 \%$ lower, between $0.7 \%$ and $0.6 \%$. The latter indicates that the plastic encapsulation of the solar cells is not enough to preserve their integrity. For this reason we consider that these devices are semi-encapsulated.

Fig. 10 shows a comparison of 3 devices (each) of the RISØ-S and RISØ-P used as references $\left(T_{100}\right)$. In general, we can observe that the device applying the functionalized copolymer, RISØ-S, presents higher reproducibility in the $I V$ curves and also in the IPCE spectra as compared to the device applying the P3HT polymer, RISØ-P. Irreproducibility is observed in the RISØ-P device and the wider IPCE peaks have been observed for other devices in this work (e.g. NREL, see Fig. 15) and have been attributed to the absorption of moisture from the atmosphere, which is provoked by the
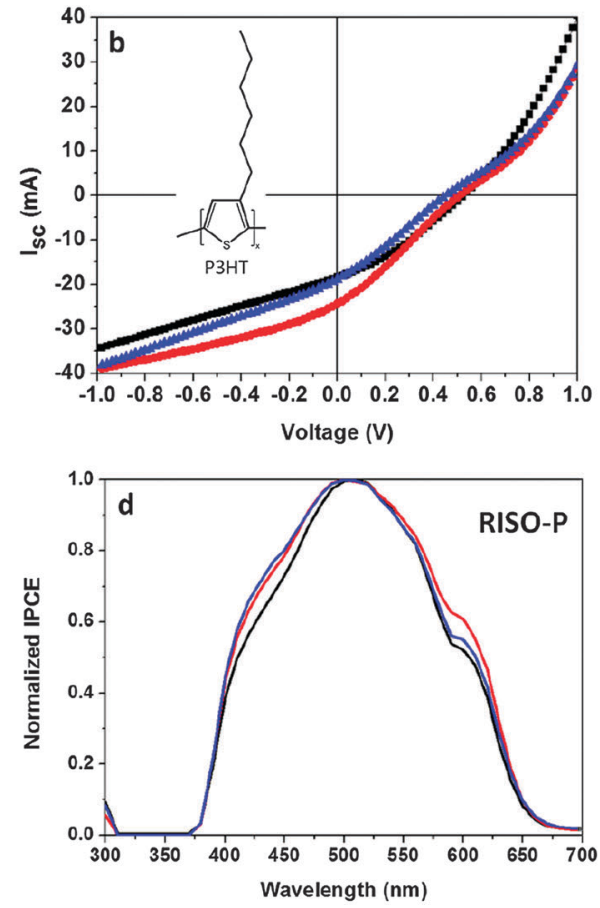

Fig. $10 I V$ curves and normalized IPCE analysis of the RISØ-S (a) and (c), and the RISØ-P (b) and (d) reference devices at $T_{100}$. 

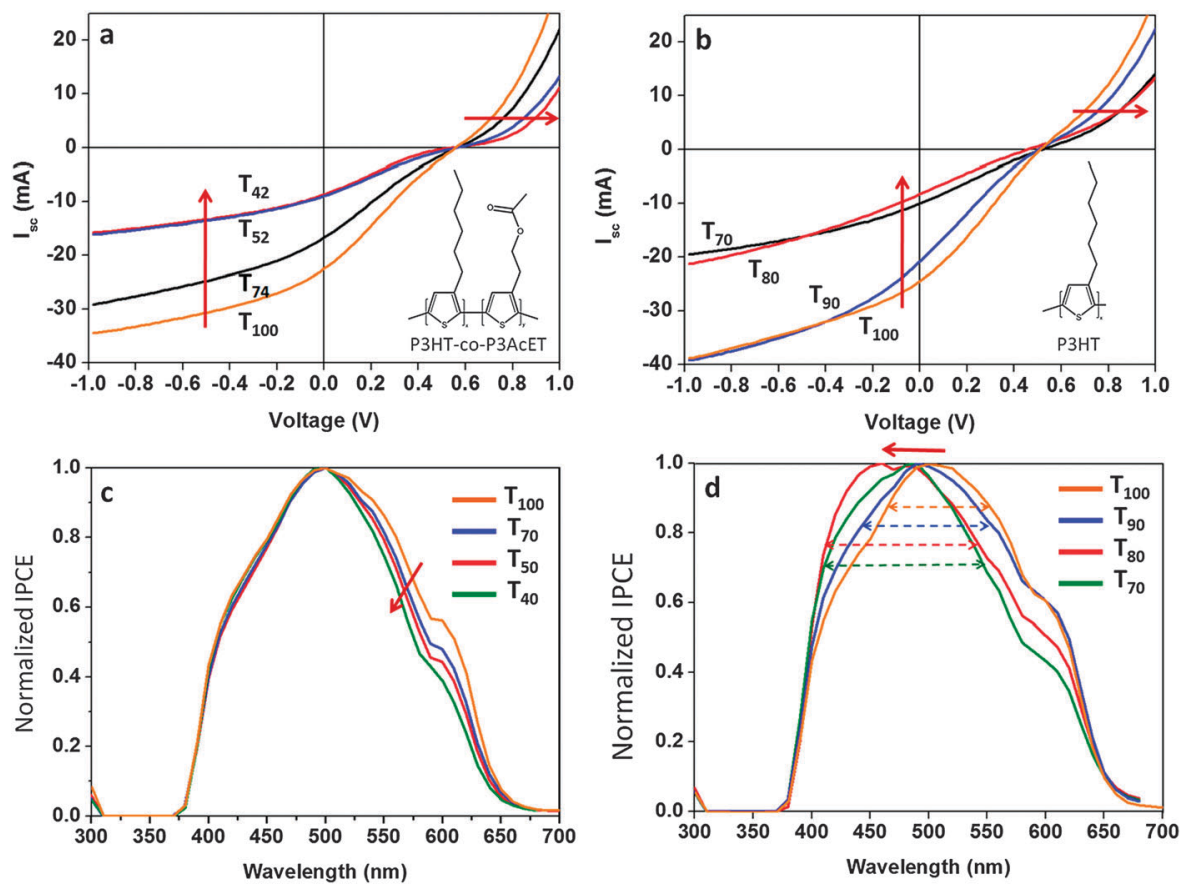

Fig. $11 I V$ curves and normalized IPCE analysis of the RISØ-S (a) and (c), and the RISØ-P (b) and (d), after the dark storage stability test at different aging time. A reference device at $T_{100}$ has been included for comparison.

presence of highly hygroscopic PEDOT:PSS. The latter can be more clearly observed by the results obtained for both devices for the dark storage stability test (Fig. 11). The test reveals that the photovoltaic response of the RISØ-S device is more reproducible than that of the RISØ-P device (as observed for the reference devices of Fig. 10). High variation in the widening of the normalized IPCE spectra for the RISØ-P devices is clearly observed even at $T_{70}$ (Fig. 11d). Although the RISØ-S spectra show some variation (in comparison with the reference devices of Fig. 10), this is observed to a much lesser extent than for the RISØ-P for the same aging time $\left(T_{40}\right)$. These results indicate that both devices are susceptible to moisture, but the RISØ-S devices seem to be much more stable. Comparison of the $I V$ curves for both devices at different aging time reveals that the RISØ-P device shows a drastic decrease in the $J_{\text {sc }}$ of the $I V$ curve at $T_{80}$, while the decay observed for the RISØ-S is smooth until $T_{50}$. The latter agrees with our observation of higher sensitivity of the RISØ-S device and is also in agreement with the response of the devices reported in our past publications. ${ }^{2,3}$ Moreover, the widening of the IPCE spectra observed for the RISØ-P device in Fig. 11d agrees with the appearance of a peak at $450 \mathrm{~nm}$ attributed to the formation of a [PEDOT:PSS.Ag] and the degradation of the $\mathrm{Ag}$ electrode. ${ }^{21-23}$ Moisture from the atmosphere could be accelerating the degradation of the device by reacting initially with the electrodes of the solar cells and degrading the photovoltaic properties over time.

An interesting observation is that the variability associated with the absorbance of moisture described above is not observed for devices that are subjected to another stability test where light and heat are present. See for example the normalized IPCE spectra in Fig. 12 that correspond to full sun stability tests for both RISØ-DTU devices. The latter supports the theory of the absorbance of moisture over time, and also demonstrates its reversible effect since moisture can be (completely or partially) eliminated under different conditions like heat, light or gas flow, among others. [A similar response has been observed also for the un-encapsulated NREL devices and the comparison with the IMEC devices, see the corresponding section 3.4.2].

Fig. 12 shows the $I V$ curves and the normalized IPCE spectra for the RISØ-DTUs devices after the full sun stability test at different aging time. The intensity of the IPCE curve decreases with increasing degradation time (not shown) as expected and in accordance with the degradation of the device over time. The normalized IPCE spectra are shown in Fig. 12a and $b$, slight changes can be observed in the intensity of the peaks above $550 \mathrm{~nm}$, which decrease with time and correspond to the degradation of the polymers. Both devices degrade in a very similar manner with the only difference that the RISØ-P sample shows a sudden and drastic drop in the PV response after $T_{50}$ that can be related to the higher sensitivity to moisture in comparison to the RISØ-S.

The absorbance of moisture in these solar cells is attributed to the hygroscopic nature of PEDOT:PSS, but semiconductor oxides like $\mathrm{ZnO}$ are also known to be hygroscopic. The latter could be the reason behind the degradation/oxidation of the electrodes like $\mathrm{ZnO}$ or $\mathrm{Ag}$ metal (also observed in our pervious works ${ }^{2,3}$ ). In addition, PEDOT can provoke the migration of $\mathrm{Ag}$ from the metal electrode (the attraction of metals like $\mathrm{Au}$, $\mathrm{Ag}$ or $\mathrm{Cu}$ by the S-atom of these type of polymers is well documented $^{21-23}$ ). The synergy of these events can incite the degradation of the metal electrodes and destroy the normal operation of the whole device. In a device like RISØ-P the failure is catastrophic and is observed much faster than in less hygroscopic devices like RISØ-S. The question here is what 

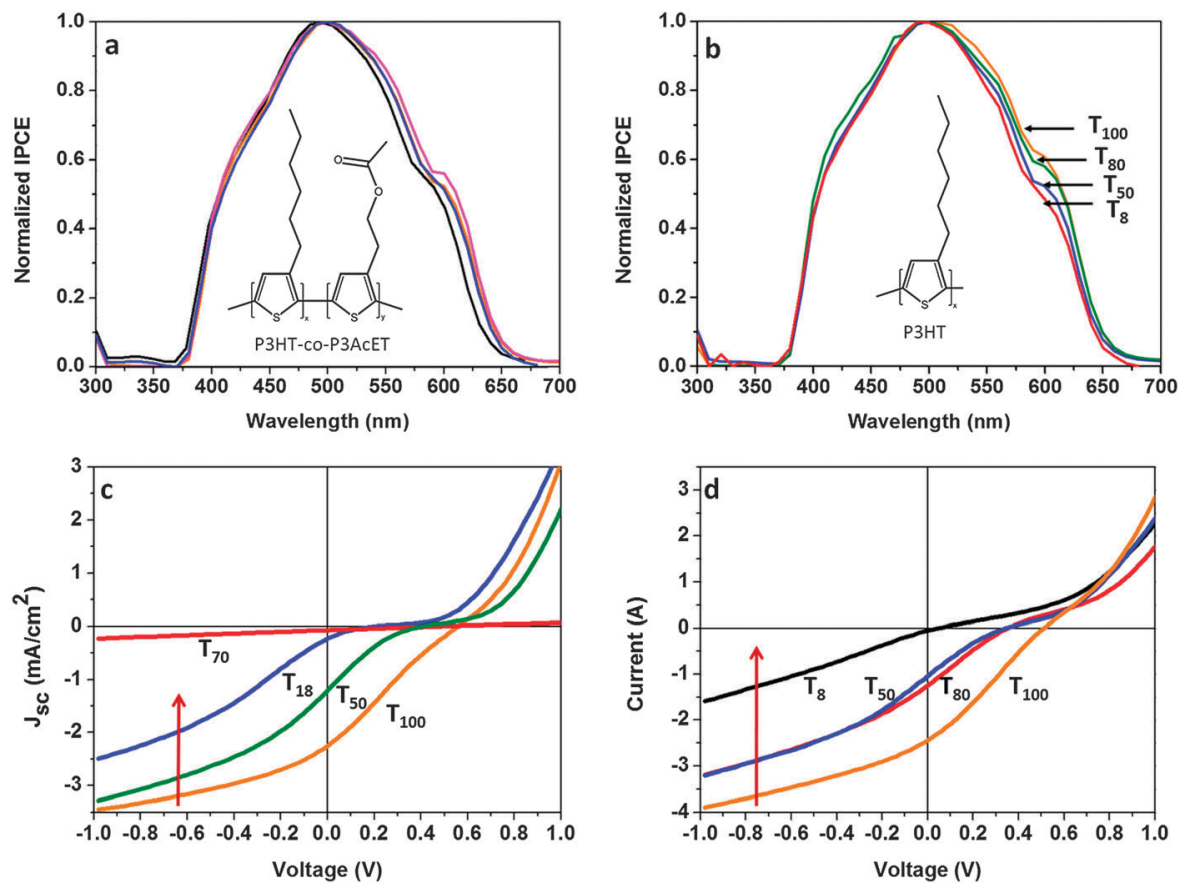

Fig. $12 I V$ curves and normalized IPCE analysis of the RISØ-S (a) and (c), and the RISØ-P (b) and (d) after the full sun stability test at different $T_{x}$. A reference device at $T_{100}$ has been included for comparison.

makes the RISØ-S device less sensitive to these reactions? The answer is clearly on the structure of the polymers that could somehow avoid an early reaction with $\mathrm{Ag}$ and slow down the degradation of the electrodes in the RISØ-S device. Finally, the fact that the IPCE graphs maintain their shape even after the PV properties of the solar cells are lost (at aging times of $T_{18}$ and $T_{8}$ ) indicates that the electrodes of the device are initially responsible for the failure of the devices and not the degradation of the active materials themselves.

\subsection{UN-encapsulated devices: NREL and IMEC}

NREL and IMEC devices, where several solar cells are included on a single substrate, allow for in-depth studies, especially on reproducibility. The similarity of the un-encapsulated NREL and IMEC devices in solar cell configuration and the design of their substrates permitted the extraction of very useful information. In both cases, the solar cells have the configuration ITO/ZnO/PCBM:P3HT/HEL/Ag, where HEL means hole extraction layer. In the case of NREL the HEL is a PEDOT:PSS layer, in the case of IMEC the HEL is $\mathrm{MoO}_{3}$. In both cases solar cells are located on the right and left sides of the substrate (6 solar cells per substrate for NREL and 12 in the case of IMEC), as can be seen in Fig. 1.

3.4.1. NREL: ITO/ZnO/P3HT:PCBM/PEDOT:PSS/Ag/Al. The NREL device is an un-encapsulated inverted OPV solar cell. It consists of 6 solar cells per substrate, and only one solar cell of the substrate was chosen to carry out the stability test at RISØ-DTU. In general, we observed an inhomogeneous degradation of the 6 solar cell devices within a single substrate. Thus it was difficult to obtain clear conclusions on the different stability tests on these devices due to the high variability in the output data.
Fig. 13 shows an example of the erratic response observed. The graphs correspond to the $I V$ curves for the NREL devices analyzed by the full sun stability test at different time. Fig. 13 includes the $I V$ curves of the device at $T_{100}, T_{71}, T_{48}$ and $T_{8}$. We incorporated two $I V$ curves for the NREL device degraded at $T_{71}$, one in red, the other one in grey. Both graphs correspond to solar cells on the same substrate degraded at the same conditions, at $T_{71}$, but the graph in grey represents the specific solar cell on the substrate chosen for the stability test carried out at RISO-DTU ${ }^{2}$, while the graph in red was chosen randomly among the best $I V$ curves obtained from all samples on the substrate. The $I V$ curves in Fig. 13 show that there is too much discrepancy in the photovoltaic response from the devices within a single substrate, thus it was impossible to arrive at a clear degradation trend with NREL samples.

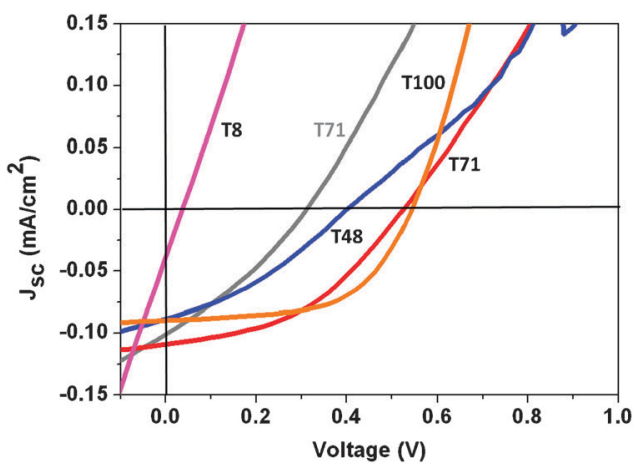

Fig. $13 I V$ curves for the NREL devices analyzed by the full sun stability test at different $T_{x}$. The $I V$ curves show two graphs at $T_{71}$. Both graphs are obtained from the same substrate degraded under the same conditions, demonstrating the erratic response observed for NREL devices. 
The general observation from the NREL devices, to be discussed in this section, is that an erratic response is observed from the samples. This response has been attributed to the combination of different issues related mainly to the fact that NREL solar cells are un-encapsulated and prone to degradation under ambient atmosphere. Our observations indicate that the solar cells are affected mainly by the high sensitivity to moisture induced by the presence of PEDOT:PSS. The degradation of the devices initiates during shipping of the devices, and it is stronger during dark storage. Moisture can be adsorbed and desorbed easily and under dark storage conditions it affects the solar cells in a random manner showing a non-linear decrease in the PV properties of the device over time. Moreover, the solar cells degrade differently depending on the position each solar cell occupies on the substrate, probably due to small difference in layer thickness during fabrication. The latter cannot be observed at the initial stages after the fabrication of the device (e.g. at the NREL home laboratory), it is only observed after several hours, under shipping and dark storage. Thus, in this section we will show the results observed for the NREL devices and the results that led to the latter conclusions, and we will analyze the possible causes behind this behaviour.

The hygroscopic nature of PEDOT:PSS. In order to understand the erratic response observed from all the NREL devices, we started by analyzing the NREL reference devices. The reference solar cells were fabricated and analyzed at the NREL laboratory, shipped to RISØ-DTU and then to CIN2 for analysis. Fig. 14 shows the IPCE analysis obtained from the 6 solar cells of the reference device labelled NREL. Our first observation was that the IPCE response varied between $36 \%$ and $56 \%$ and that it was somehow divided into two series of curves: the highest IPCE values (48-56\%) were observed for solar cells labelled 1 to 3 and the smallest values (36-38\%) for devices 4 to 6 as shown in Fig. 14a. Apart from this, the normalized IPCE curves show a very reproducible shape (Fig. 14b), an indication of materials integrity within the devices in the substrate. Nevertheless, the different intensity of the IPCE graphs (Fig. 14a) indicates that some external factors could probably be affecting the device, which at the same time affects the overall PCE from the solar cells (see Fig. 14c).

Comparison of the photovoltaic response obtained for the same substrate at the NREL home laboratory and at CIN2 permitted us to see that PCEs values decreased in a non-linear manner from what was measured at the home NREL laboratory. Moreover, the variation observed in the PCE of the devices measured at the home laboratory was between 3-6\% (PCEs between 2.1 and 2.6\%), while at CIN2 these differences were observed to be larger, between $23 \%$ and $37 \%$ (PCEs between 1.6 and $2.4 \%$ ). At this point, we realized that the devices were shipped from the NREL home laboratory to RISØ-DTU and then to CIN2 for analysis, and that the time that passed between measurements was more than a month $(>700 \mathrm{~h})$. During all the shipping time, the conditions at which the devices were maintained were mostly dark storage under ambient air. These conditions are similar to the dark stability test carried out at RISØ-DTU, with the difference
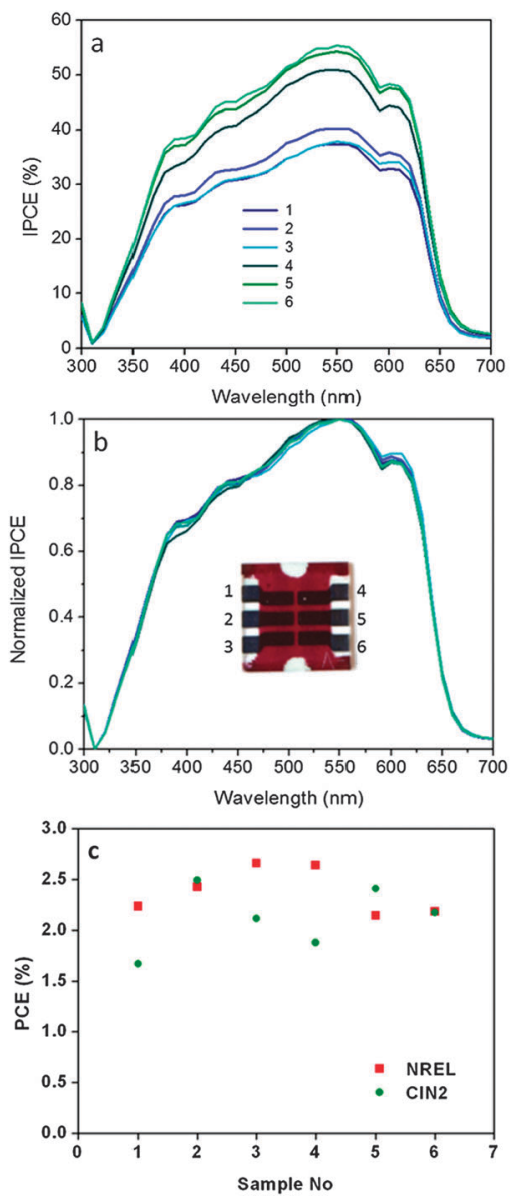

Fig. 14 IPCE analysis for the reference device NREL $\left(T_{100}\right)$. (a) IPCE spectra, (b) normalized IPCE spectra and (c) PCE measured at the NREL home laboratory and at CIN2. Samples analyzed at NREL right after preparation, at CIN2 after shipment (after about $700 \mathrm{~h}$ under ambient atmosphere).

that the stability test was carried out for periods of time up to 2.5 months (or $1745 \mathrm{~h}$ ) at a single location. Thus, the explanation for this response can be found from the dark storage stability test as will be shown next. The response of a NREL device to dark storage at $T_{20}$ (or $1475 \mathrm{~h}$ storage in the dark) is shown in Fig. 15. The most interesting observation is that the IPCE spectra show high variation in peak intensities and width, maintaining the same shape as shown by the normalized IPCE graphs (Fig. 15a). Surprisingly, the response was only observed for NREL devices stored in the dark (see also ESI $\dagger$, Fig. S3). It was not detected for NREL devices subjected to any type of light tests (fluorescent or full sun stability tests). The latter indicates that there is an external factor that affects the NREL devices under dark storage conditions, and it can be, at least partially, eliminated when the devices are subjected to irradiation tests (light and/or heat). Analyzing the response of a very similar un-encapsulated device, IMEC, at the same dark storage conditions of $T_{20}$ (Fig. 15b), we observed that the drastic intensity variation in the normalized IPCE peaks observed for the NREL device is not present here. The normalized IPCE spectra of the IMEC devices show some variation in peak intensity (e.g. below $400 \mathrm{~nm}$ or at $625 \mathrm{~nm}$ ), but no variation in the width of the peaks is observed (see Fig. 15b). 

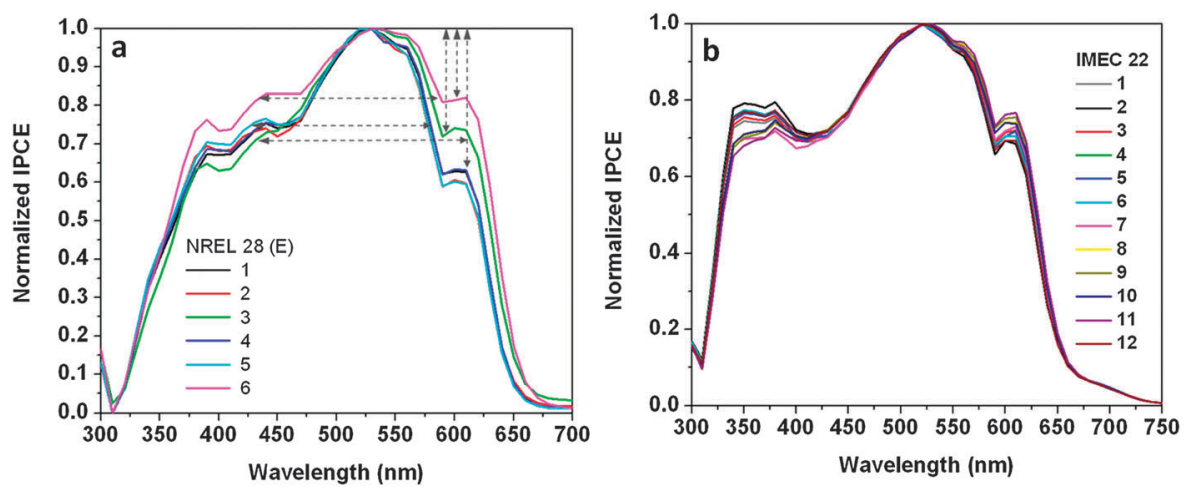

Fig. 15 IPCE analysis of reference devices from NREL (a) and IMEC (b) after the dark storage stability tests at $T_{20}(1745 \mathrm{~h})$.

The only difference between the solar cell materials used by the IMEC and the NREL devices is the PEDOT:PSS layer. In IMEC solar cells, the PEDOT:PSS layer has been substituted by a thin layer of $\mathrm{MoO}_{3}$. Thus, we attribute the behaviour observed in the NREL samples to the presence of the PEDOT:PSS layer.

PEDOT:PSS has been shown to be highly hygroscopic. Several works have also reported on the reversible water uptake of PEDOT that affects its conductivity properties. ${ }^{42,43}$ In addition, PEDOT has been proved to be able to oxidize the cathode electrode. ${ }^{44}$ It has also been related to the formation of pinholes and the catastrophic failure of $J_{\mathrm{sc}}$ observed in inverted OPVs analyzed in air leading to the reduction of device lifetime. ${ }^{45,46}$ Although semiconductor oxides like $\mathrm{ZnO}$ or $\mathrm{MoO}_{3}$ are also known to be sensitive to moisture, ${ }^{47-51}$ the $\mathrm{MoO}_{3}$ layer has shown to be much more stable to humidity than the PEDOT polymer ${ }^{44-46,52,53}$ and reports on the improvement of device lifetime can already be found in the literature when the $\mathrm{MoO}_{3}$ layer is used instead of PEDOT:PSS. ${ }^{54}$

All the aforementioned detrimental effects on OPVs observed when PEDOT:PSS is applied have also been observed for the NREL devices analyzed in this collaborative work as already reported. ${ }^{3,5}$ Moreover, detailed analysis by image tests reported in our second publication ${ }^{3}$ demonstrates the catastrophic failure (by corrosion in air) of the contact electrodes of the un-encapsulated NREL devices. This observation agrees with our IPCE (and PCE) results and thus we attribute the hygroscopic nature of PEDOT:PSS to be the main cause (but not the only one) behind the erratic response observed for the NREL devices. Humidity affects the solar cell materials randomly and reversibly and different degree of degradation can be observed for each solar cell in a substrate.

Effect of the position of the solar cell within a substrate. We have also observed that the photovoltaic response of the NREL devices depends to a great extent on the position of the solar cell within a substrate as shown in Fig. 16, where the analyses of randomly-chosen devices for each type of stability test are shown. Especially in the case of full sun stability tests, the devices with the lowest IPCE values were observed to be completely degraded while in some cases, the rest of the devices maintained a relatively good photovoltaic response. In the case of NREL devices, many of the solar cell substrates showed this trend, and the response was usually dependent on the side of the substrate, as shown in Fig. 16. The solar cells with the highest PCE are identified in green (on the device image and in the graph), the solar cells with the lowest PCE are plotted in blue, and the solar cell chosen (among the 6 of the substrate) for each stability test carried out at RISØ-DTU has been plotted in red.

The relation between the efficiency of the solar cell and the position it occupies in the substrate has been recently reported in the literature for spin coated devices. ${ }^{55}$ Yet, we believe that the variable response observed for the devices is the contribution of several factors, with the hygroscopic nature of PEDOT:PSS being one of the most harmful for the solar cells. We believe that the time that passed between the fabrication of the devices at the NREL home laboratory and the relative humidity present during the shipment and storage is a key factor for the proper functionality of these devices. Humidity can incite irreversible damage to the device but it can by itself provoke the complete destruction of the solar cell electrode when stored in the dark in air. The damage to the device probably started during shipment then the inhomogeneous dispersion of the solar cell layers during fabrication (e.g. small differences in thickness of any layer, PEDOT:PSS or active materials, also differences in ITO etching, etc.) can do the rest, but further analyses will be required in order to find the exact cause of this trend. All these factors are clearly observed in devices stored in the dark in air as shown in Fig. 17. The IV curves and IPCE analysis of the device NREL after dark storage until $T_{40}$ are shown in Fig. $17 \mathrm{a}-\mathrm{c}$. The variation in PCE is observed to be very high, with values ranging between $0.7 \%$ and $2.1 \%$ when analyzed at CIN2. We also observed that the behaviour affects the solar cells randomly and reversibly: the PCE value changes up and down when measured at different laboratories as observed in Fig. 17c. The degradation is acute depending on the place the solar cell chosen for the stability test is located in the substrate. In some cases some devices can preserve their good photovoltaic properties (as device 5 in Fig. 17) but in others a device can be highly degraded under the same storage conditions (as seen in device 3 in Fig. 17). In this case, device 5 was the one chosen for the stability test, and it is observed to be the one with the highest photovoltaic response among all devices.

This observed effect is important since these differences have a relation with the stability of the solar cell chosen (within the substrate) for the lifetime studies reported in this collaborative work. It is clear, by looking at the results in Fig. 17, that the 

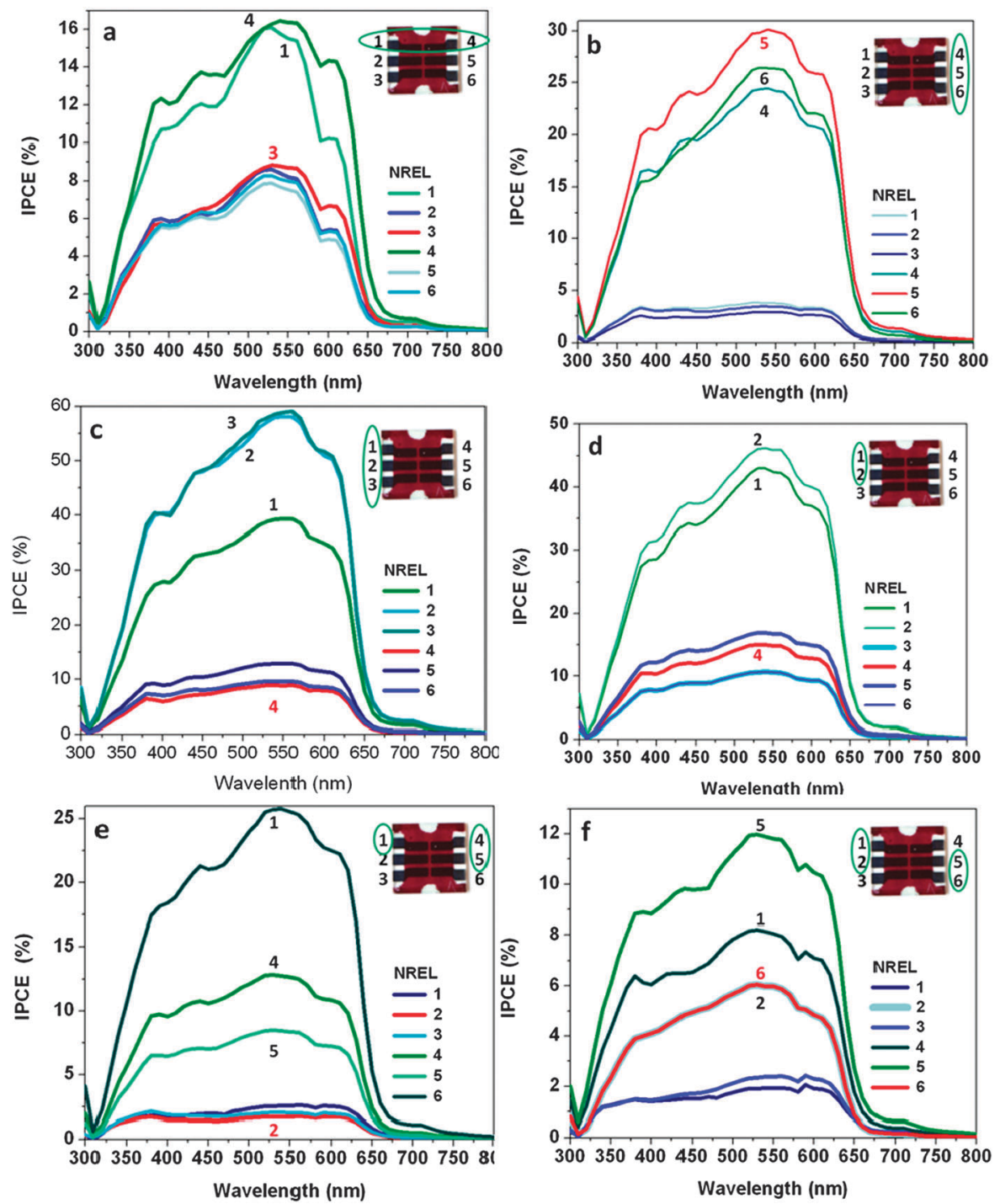

Fig. 16 IPCE analyses of NREL randomly selected devices after different stability tests. (a) NREL under dark storage $T_{20}$; (b) NREL under dark storage $T_{40}$, (c) NREL under low intensity fluorescent light at $T_{30}$, (d) NREL under low intensity fluorescent light at $T_{72}$, (e) NREL under full sun at $T_{70}$ and (f) NREL under full sun at $T_{7}$. Green circles indicate the devices with the highest IPCE value among the substrates, graphs in red correspond to the solar cell selected to carry out the corresponding stability tests at RISØ-DTU.

response of the solar cell to the dark storage test is completely dependent on the device chosen for the analysis within the substrate. But the response is not exclusive of the stability test under dark conditions, it is also observed in other stability tests. To illustrate the effect of the position of the solar cell in other stability tests, we show in Fig. 18 the response of a NREL device after the full sun stability aging at $T_{71}$. Device 2 (in red) was the one used for the stability test as reported in our first paper. ${ }^{2}$ Analyzing the photovoltaic values obtained for the solar cells within the substrate at the home NREL laboratory, at RISØ-DTU and CIN2 we observed an increase in the variability of the PCE within the devices in the substrate, from very low variability of $3.8 \%$ when freshly prepared at NREL, up to $30 \%$ and $66 \%$ variability when analyzed at RISO-DTU and CIN2 respectively. The variation observed after the stability test when analyzed at CIN2 corresponds to PCE between $0.88 \%$ (device 2) and $2.59 \%$ (device 6) among the solar cells in the same substrate. The normalized IPCE spectra in Fig. 18a show that the most degraded devices, devices 1, 2 and 3, present a distortion in the $\mathrm{ZnO}$ peak at $340 \mathrm{~nm}$ while the rest of the IPCE peaks remain almost unaffected (the effect is also observed in Fig. 17a). The latter is an indication that the degradation of the solar cells could be initiated on the electrodes and not in the main active materials. In this device, solar cell 2 was the one chosen for the stability test at RISØ-DTU, but it is also the solar cell with the worst PV response at $T_{71}$. While choosing device 6 could lead to a completely different conclusion on stability. We have also observed that since the solar cells analyzed at NREL showed very reproducible response right after fabrication (Fig. 18d), it was impossible to know initially which solar cell was the best one to carry out the stability test or which one could present these problems. The device chosen at RISØ-DTU for the stability test was the solar cell with the best photovoltaic response at the moment of analysis at RISØ-DTU [more examples are included in Fig. S3 and S4, ESI†]. 

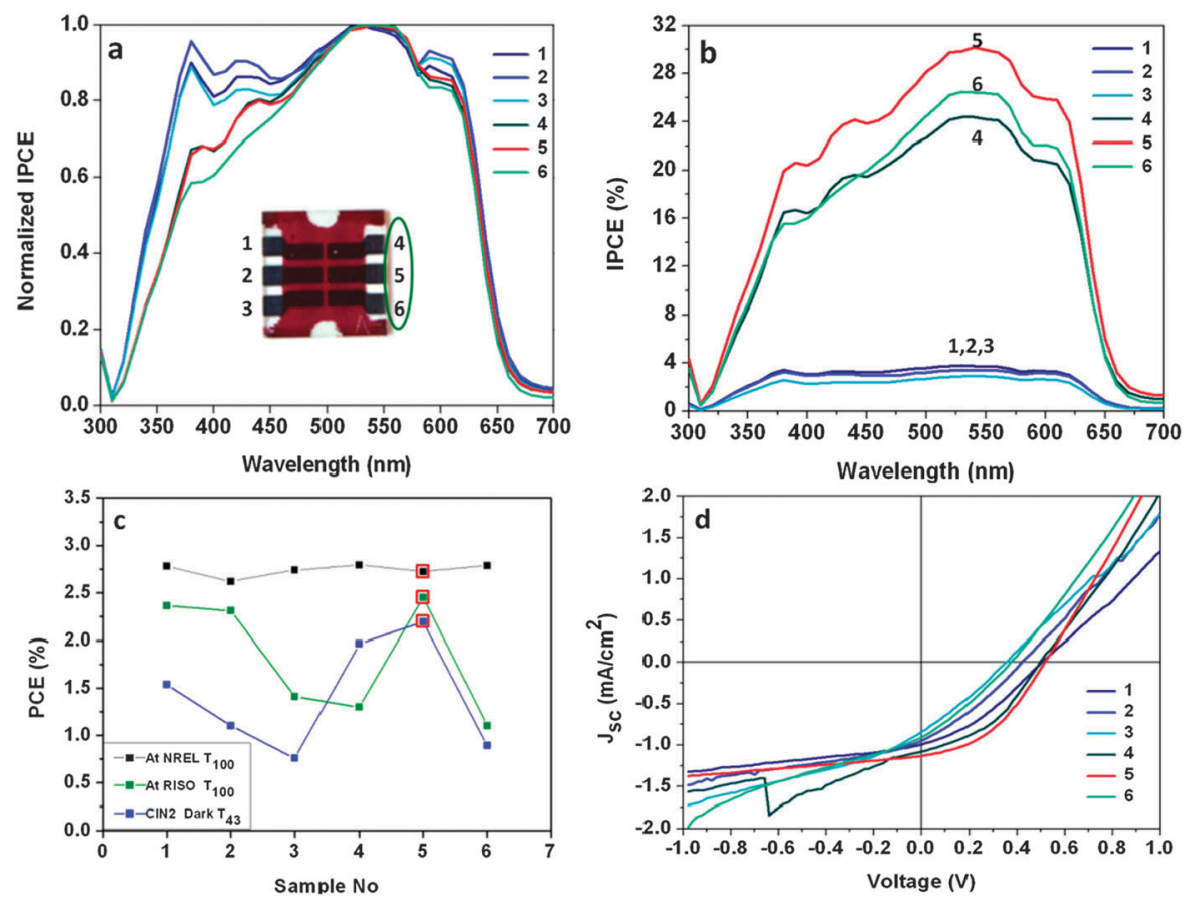

Fig. 17 Dark storage stability test at $T_{40}$ for the device NREL. Green circles indicate the devices with the highest IPCE value among all the samples in the substrate, graphs in red correspond to the solar cell selected to carry out the corresponding stability tests at RISØ-DTU.

The Ag/Al electrical contacts. The $200 \mathrm{~nm}$ thick $\mathrm{Ag} / \mathrm{Al}$ electrodes of the NREL samples are used as the electrical contact which connects the device with the measurement equipment. We observed that the longer the degradation time of the NREL samples the electrical contact with the devices became more difficult. At the same time, higher error was observed in the IPCE response in comparison with the $J_{\mathrm{sc}}$ obtained from the $I V$ curves. The $\mathrm{Ag} / \mathrm{Al}$ electrode can easily be scratched from the substrates due to its reduced thickness $(200 \mathrm{~nm})$. This can be partially contributing to the erratic response we observed for the NREL samples. Under a continuous testing condition, like in our first publication, the problem with the electrical connection resulted in high noise level of the output data. ${ }^{2}$ In our case, a connection failure results in flat IPCE spectra. Since the IPCE analysis is a punctual measurement, the electrical connection problem was easily resolved by adjusting the clip connectors. Nevertheless, a non-optimal electrical contact can have some influence on the final IPCE result. To illustrate the latter we can analyze Fig. 18 in more detail. The trend observed in the IPCE (Fig. 18b) is in good agreement with the trend observed for the PCE (Fig. 18d): solar cells 1-3 show lower PCE than solar cells 4-6. Nevertheless, solar cell 4 should have higher PCE than solar cell 5, the same for solar cells 1 and 3 . We believe that these small changes in the NREL results are due to the problem with electrical connections, but further analysis must be needed to demonstrate the latter. We know that this problem can be largely eliminated by painting a silver ink on the contact pads as was done for the IMEC samples described in Section 3.4.2.

In situ IPCE analyses. The in situ IPCE analysis carried out on the NREL device is shown in Fig. 19. The IPCE spectra
(Fig. 19a) show that the whole spectra decrease in intensity with time, an indication of the reversible exchange of oxygen from organic semiconductor materials as reported. ${ }^{26-31}$ The formation of a CTC between organic semiconductors and oxygen from the atmosphere, CTC $\left[\mathrm{P} 3 \mathrm{HT} \cdot \mathrm{O}_{2}{ }^{--}\right.$], is clearly observed at around $525 \mathrm{~nm}$. The peak has been reported to be reversible, and to increase the photovoltaic properties of $\mathrm{OPVs},{ }^{27}$ in good agreement with the IPCE response observed in Fig. 19a. These features can be observed more clearly in the normalized IPCE spectra of Fig. 19b. The wavelength region above $500 \mathrm{~nm}$ corresponds to the P3HT polymer; the shift observed for the peak at $530 \mathrm{~nm}$ towards $560 \mathrm{~nm}$ is well known to be due to the formation of a reversible CTC between organic semiconductors (like $\mathrm{C}_{60}$ or $\mathrm{P} 3 \mathrm{HT}$ ) and oxygen from the atmosphere. ${ }^{26-31}$

The normalized IPCE spectra (Fig. 19b) also show the decrease of the peak at $360 \mathrm{~nm}$ which corresponds to the release of oxygen from the $\mathrm{ZnO}$ (to $\mathrm{ZnO}_{1-x}$ ) crystalline structure. This phenomenon has been extensively described for $\mathrm{ZnO}$ and also for other semiconductor oxides in solar cells. ${ }^{56-58}$ The application of the in situ IPCE technique to visualize this effect has been recently reported for hybrid solar cells applying doped and undoped oxides with a similar response. ${ }^{6,59}$

Polymer S-atom bonding to metallic Ag from the electrode. Finally, we have also observed in Fig. 19 that although the band below $400 \mathrm{~nm}$ from the $\mathrm{ZnO}$ decreases when the device is subjected to the $\mathrm{N}_{2}$ atmosphere, the absorption band at $\sim 430 \mathrm{~nm}$ is maintained. We have recently proposed the formation of a S-oxide bond, in the latter case between the interface of P3HT and $\mathrm{TiO}_{2}$, which resulted in a similar behaviour, the absorption peak of the oxide decreased under $\mathrm{N}_{2}$ atmosphere and a band that appeared at $\sim 350 \mathrm{~nm}$ was maintained unaffected. ${ }^{6,41}$ 

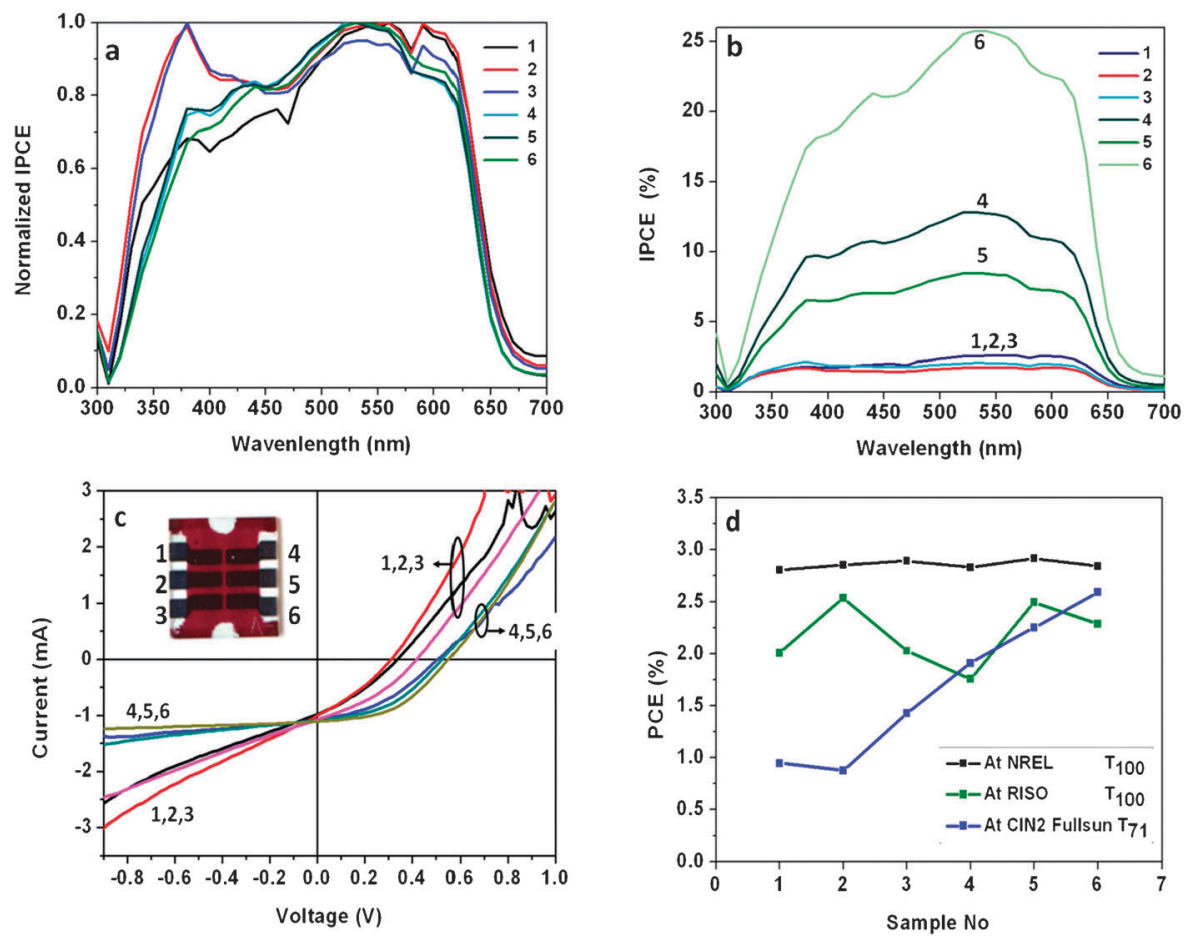

Fig. 18 Analysis of the 6 solar cells of the NREL substrate after the full sun stability test at $T_{71}$. Among all solar cells, device 2 was the one chosen initially to carry out the stability tests at RISØ-DTU (in red).

In the case of an inverted OPV like NREL (ITO/ZnO/ P3HT:PCBM/PEDOT:PSS/Ag/Al), besides the $\mathrm{S}-\mathrm{ZnO}$ bonding between $\mathrm{ZnO}$ and the S-atom of the P3HT, the formation of a chemical bond between the Ag and the PEDOT:PSS is possible due to the attraction of the S-atom of PEDOT towards Ag. ${ }^{25}$ A nanocomposite of the type [PEDOT:PSS.Ag] is known to absorb in the UV-Vis at around $\sim 420-450 \mathrm{~nm} .{ }^{21-23}$ Since the compound doesn't have oxygen that can be released under $\mathrm{N}_{2}$, the absorption band will not disappear in agreement with Fig. 19b. Moreover, the attraction of the S-atom from polymers like PEDOT and P3HT and the observation of the IPCE peak at $430 \mathrm{~nm}$ are in well agreement with the degradation of the $\mathrm{Ag}$ metal contacts (by electro-migration of Ag into the PEDOT:PSS layer). The latter can provoke device shunting, as observed for the NREL devices analyzed by our imaging characterization techniques and reported in our second work, Rösch et al. ${ }^{3}$

In conclusion, the NREL devices have been demonstrated to be highly sensitive to humidity in agreement with the reversible water uptake known for PEDOT:PSS. The presence of a peak in the IPCE spectra at $\sim 430 \mathrm{~nm}$ indicates the interaction between Ag and [PEDOT:PSS]. These two factors could initiate the degradation of the solar cell at the electrodes, reducing the flux of current through the solar cell over time. Although the device is no longer operative, the integrity of the solar cell materials is preserved as observed by the homogeneous IPCE spectra (normalized). Moreover, the position of the solar cells within the substrate together with the random water uptake of PEDOT:PSS provokes the degradation of the solar cells and is highly variable in the cells located on the same substrate. Finally, we should also draw attention to the difference in the relative humidity $(\mathrm{RH} \%)$ per year that characterizes the region where the home NREL laboratory is located (Colorado, USA, RH 40-50\% per year) and the one at the RISØ-DTU laboratory (Roskilde, DK, RH $80-90 \%$ per year) where the stability tests were carried out. The hygroscopic nature of PEDOT:PSS and the high difference in $\mathrm{RH} \%$ between
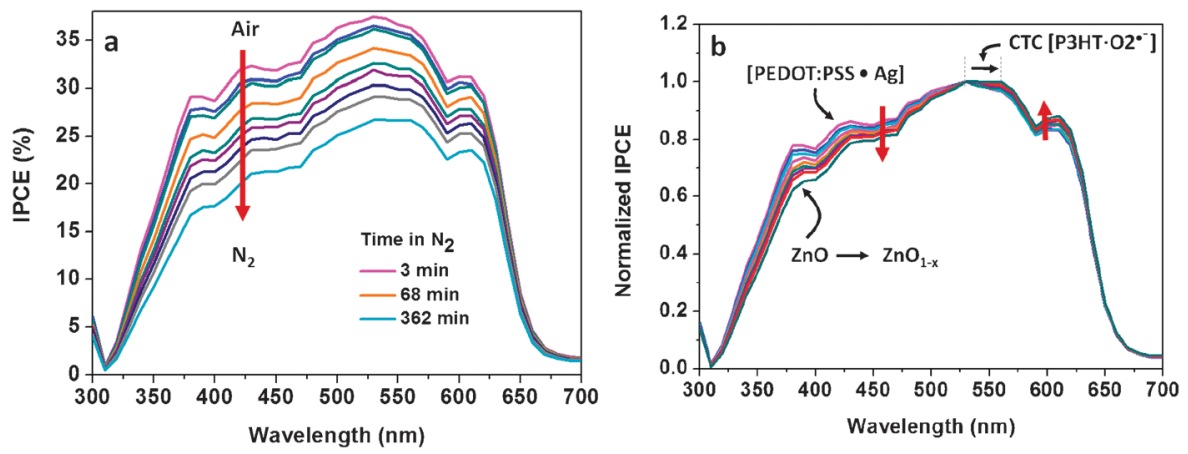

Fig. 19 In situ IPCE analysis of an NREL device (a) and the normalized IPCE spectra (b). 
these laboratories can explain the discrepancy in lifetime observed for the NREL devices analyzed in ambient atmosphere at the home NREL laboratory ${ }^{52}$ and at RISØ-DTU as reported in our first publication. ${ }^{2}$

3.4.2. IMEC: ITO/ZnO/P3HT:PCBM/ $/ \mathrm{MoO}_{3} / \mathrm{Ag} / \mathrm{Al}$. The IMEC device is an inverted OPV. The main difference with the NREL device described before is the replacement of the PEDOT:PSS layer by a thin $\mathrm{MoO}_{3}$ layer, which is well known to confer better stability towards ambient atmosphere (especially humidity). ${ }^{54}$ Although the hygroscopic PEDOT:PSS is known to be catastrophic for organic solar cells, ${ }^{44-46}$ we should keep in mind that semiconductor oxides like $\mathrm{ZnO}$ and $\mathrm{MoO}_{3}$ can also be sensitive to moisture. ${ }^{47-51}$ In fact, semiconductor oxides are used as humidity sensors ${ }^{50,51}$ and thus the ambient atmosphere also exerts an important effect on the IMEC devices. In general, most of the features observed for the NREL devices were observed for the IMEC devices. In the IMEC devices, however, the response was observed to be much more reproducible and 'ordered' which permitted the explanation of many more aspects of the degradation. It also permitted the confirmation of the results observed for the NREL devices and the catastrophic nature of the PEDOT:PSS layer in those devices. Thus, IMEC devices appear much more reproducible and we were able to compare devices through different light stability tests at one aging time, $T_{x}$, as well as the degradation of the device at full sun at different aging times.

The analysis of the IPCE reference devices $\left(T_{100}\right)$ of IMEC samples resulted in some variation between solar cells in the same substrate, but in general, very good reproducibility was observed as can be seen from the normalized IPCE spectra. The main features of an encapsulated and an un-encapsulated device are shown in Fig. 20. Devices were analyzed at $T_{100}$. Device (a) and (b) refer to un-encapsulated and encapsulated solar cells respectively. Comparison of both spectra shows two clear features for the un-encapsulated device: first, the widening of the absorption region below $400 \mathrm{~nm}$ and second, the red shift observed for the maximum IPCE peak from $535 \mathrm{~nm}$ when encapsulated to $560 \mathrm{~nm}$ when no encapsulation is present (peaks marked with arrows). The widening of the region below $400 \mathrm{~nm}$ corresponds to the $\mathrm{ZnO}$ and $\mathrm{MoO}_{3}$ absorption region. ${ }^{60}$ The latter indicates that the ambient atmosphere is modifying the properties of these oxides, in agreement with the sensitivity towards humidity known for several semiconductor oxides, ${ }^{47,50}$ among which are $\mathrm{MoO}_{3}{ }^{49,51}$ and $\mathrm{ZnO}{ }^{48}$

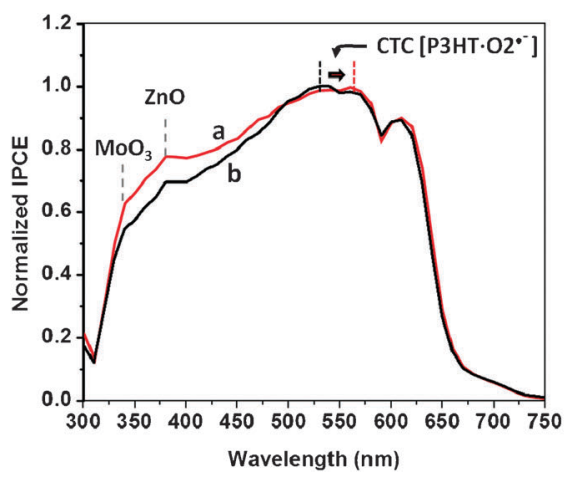

The shift observed for the maximum IPCE peak shown in Fig. 20 is associated to the interaction of organic semiconductors, like P3HT, towards oxygen. ${ }^{27,28}$ Here it is important to remark that other peaks that correspond to the P3HT, above $550 \mathrm{~nm}$, are maintained unaffected in shape and intensity. The latter also agrees with the fact that the formation of a CTC between P3HT and oxygen, CTC $\left[\mathrm{P} 3 \mathrm{HT} \cdot \mathrm{O}_{2}{ }^{\bullet-}\right]$, from the atmosphere does not imply degradation, since the CTC is known to be reversible, and only the long-term light irradiation of the CTC compromises P3HT stability. ${ }^{27,28}$

The advantage of $\mathrm{MoO}_{3}$. The reference devices from IMEC behave very similar to devices from NREL. The PCE analyzed at the IMEC laboratory for the reference devices $\left(T_{100}\right)$ was observed to be higher than what was measured at CIN2 (Fig. 21). The variability found in the PCE values was also observed to decrease randomly among the devices, and it has been attributed to the time that passed between device fabrication, shipment to RISØ-DTU and to CIN2 (more than a month difference). The IPCE analysis showed also differences between devices but we did not observe any difference in the IPCE intensity that depended on the place of the solar cell in the substrate as observed for the NREL devices. The normalized IPCE spectra show very good reproducibility as shown in Fig. $21 \mathrm{~b}$.

The decrease in PCE (and the random variability) was also observed for the devices used for the dark storage stability tests (Fig. 22). Devices measured at the IMEC home laboratory at $T_{100}$ showed larger PCE in comparison with the values observed at RISØ-DTU before the stability test (Fig. 22e). Very useful information was acquired by analyzing the results obtained from the dark storage tests at $T_{69}, T_{49}$ and $T_{28}$ as shown in Fig. 22. The first conclusion is the good reproducibility of the normalized IPCE spectra for each aging time (Fig. 22d). The latter indicates that, within an error, the solar cells degrade in a similar way in the substrate.

Analyzing the IPCE graphs in Fig. 22a-c (without normalization), we can clearly observe that the longer the storage in the dark the lower the IPCE value and also the higher the variability among the solar cells within the substrate. In Fig. 22c we observed that the differences with respect to the position of the solar cell within the substrate start to appear at this stage, the devices 1 to 6 (and also device 12) being the ones showing the worst response. The effect was observed only after many hours under dark storage, almost at the end of the

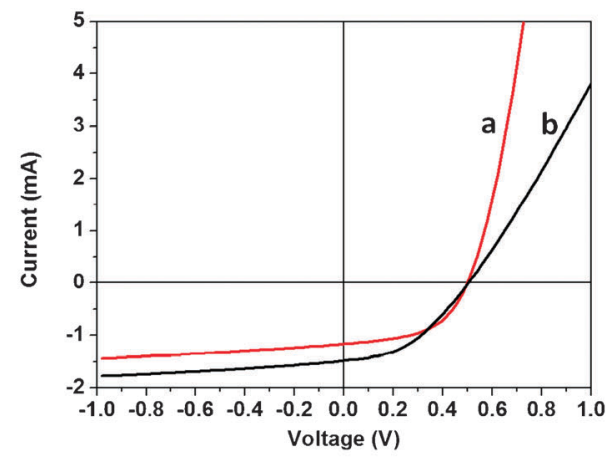

Fig. 20 Normalized IPCE spectra (left) and the corresponding $I V$ curve (right) of IMEC solar cells at $T_{100}$. (a) Un-encapsulated, (b) encapsulated. 

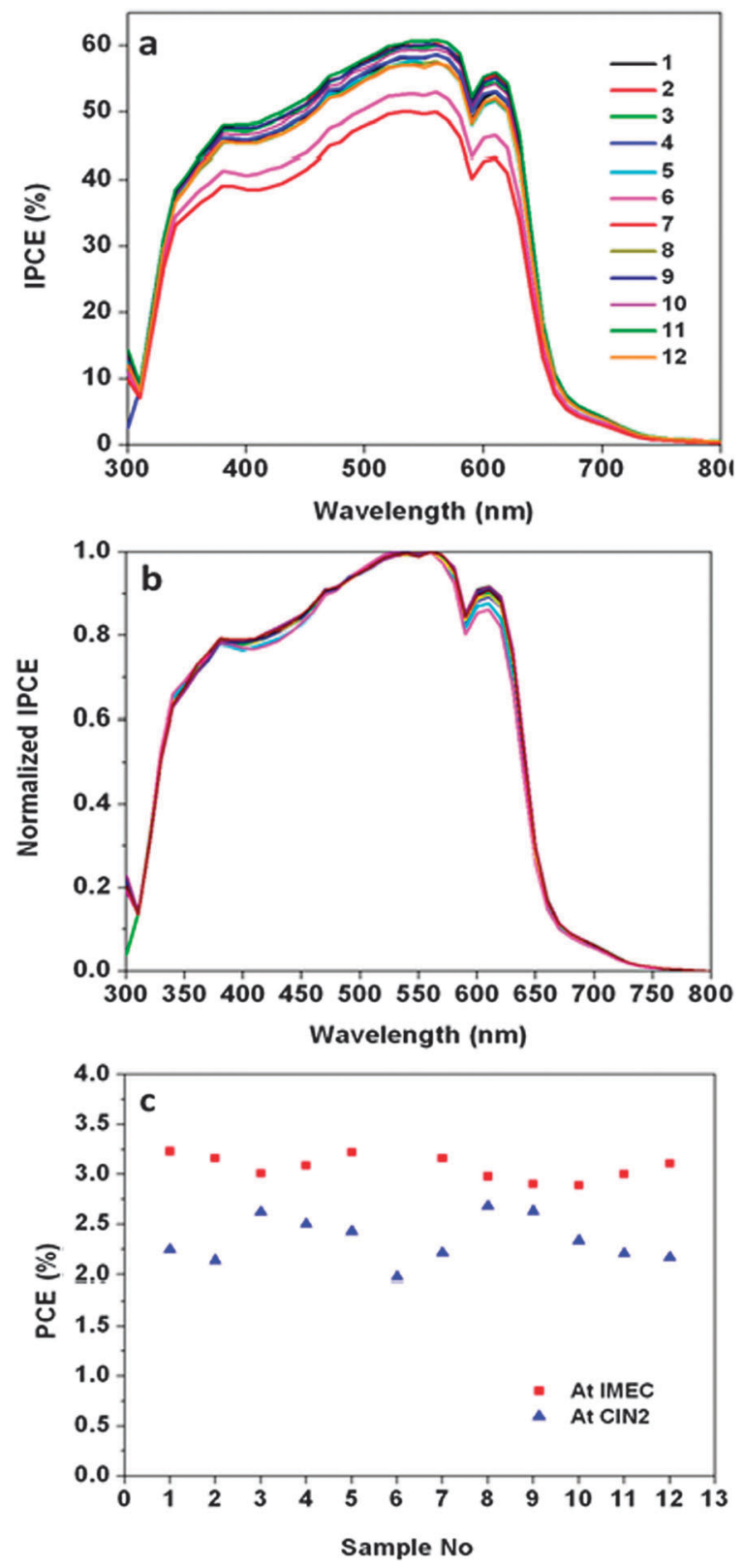

Fig. 21 IMEC reference device analyzed at $T_{100}$. (a) IPCE analysis, (b) normalized IPCE analysis and (c) the PCE obtained at IMEC (freshly prepared) and at CIN2 (after about $1475 \mathrm{~h}$ in ambient atmosphere).

lifetime of the device ( $T_{28}$ or $1745 \mathrm{~h}$ ). In the NREL devices this behaviour was observed to be very drastic and appeared randomly in the majority of all the devices independently of the aging time. Thus, we observe that the ambient atmosphere is crucial for NREL and IMEC devices and in both cases it has a nonuniform effect on the position of the solar cell on the substrate. The effect is observed much earlier (or faster) for the NREL devices, and later (or slower) for the IMEC devices, in agreement with the highly hygroscopic nature of the PEDOT:PSS layer in comparison with $\mathrm{MoO}_{3}$. It is important to mention that with IMEC devices we observed that the wavelength region below $400 \mathrm{~nm}$, corresponding to the $\mathrm{ZnO}$ and $\mathrm{MoO}_{3}$ layers, was greatly influenced by the dark storage.
The peaks at $340 \mathrm{~nm}$ and $380 \mathrm{~nm}$ (especially the peak at $340 \mathrm{~nm}$ that corresponds to $\mathrm{MoO}_{3}$ ) increase with the dark storage time, an indication that the oxides layers could be slowly adsorbing moisture from the atmosphere. The latter can also promote the degradation of the electrodes or other internal reactions in the device, something that cannot be determined by this technique but agrees with the data reported in our second work. ${ }^{3}$ Fig. $22 \mathrm{f}$ shows that some solar cells present low PCE but the corresponding IPCE spectra do not match with this trend since it is very similar to the rest of the devices in the substrate. The latter indicates that an external factor (such as electrode damage) could be affecting the device response, and is supported by the localized degradation of the wavelength region that corresponds to the electrodes (below $400 \mathrm{~nm})$.

Fig. 23 shows the effect of full sun irradiation on IPCE analysis (Fig. 23a) as well as the corresponding $I V$ curves (Fig. 23b) for an un-encapsulated IMEC solar cell. In general, photovoltaic properties of the IMEC device decrease with time under full sun irradiation conditions, in agreement with our previous articles. ${ }^{2,3}$ The IPCE analysis shown in Fig. 23 reveals that the causes of degradation are related to the oxide electrodes, $\mathrm{ZnO}$ and $\mathrm{MoO}_{3}$, as indicated by the steady decrease of the peaks below $400 \mathrm{~nm}$. Another important factor is the degradation of the IPCE peaks that correspond to the P3HT at $560 \mathrm{~nm}$ and $600 \mathrm{~nm}$ (with respect to the reference device) which translates to a decrease of the current density of the $I V$ curves. The shift of the maximum IPCE peak over time (due to the decrease of the maximum IPCE peak at $575 \mathrm{~nm}$ (reference) and the emerging of a peak at $525 \mathrm{~nm}$ ) indicates that the $\left[\mathrm{P} 3 \mathrm{HT} \cdot \mathrm{O}_{2}{ }^{\bullet-}\right]$ CTC disappears with longer irradiation times due to degradation of the P3HT.

In situ IPCE. The features observed in the in situ IPCE analysis of the NREL devices described in the section above are the same for the IMEC devices with only two important differences. The IMEC device applies a thin layer of $\mathrm{MoO}_{3}$ in replacement of the PEDOT:PSS layer of the NREL devices (Fig. 24a). The $\mathrm{MoO}_{3}$ layer is a semiconductor oxide that absorbs at wavelengths of $350 \mathrm{~nm}$ and below. ${ }^{7-10}$ It also shows oxygen-release and exchange properties as reported by Mestl et al. ${ }^{61}$ Thus, the normalized IPCE spectra of the IMEC devices shown in Fig. 24b present two peaks below $400 \mathrm{~nm}$, one at $340 \mathrm{~nm}$ that corresponds to the $\mathrm{MoO}_{3}$ and a second one that corresponds to the $\mathrm{ZnO}$ at $380 \mathrm{~nm}$. Both peaks decrease steadily with time under an inert $\mathrm{N}_{2}$ atmosphere due to the release of oxygen from their structure $\left(\mathrm{ZnO} \rightarrow \mathrm{ZnO}_{1-x}\right.$ and $\left.\mathrm{MoO}_{3} \rightarrow \mathrm{MoO}_{3-x}\right)$, a characteristic of many semiconductor oxides. ${ }^{6,56-59}$ Comparison between NREL and IMEC devices indicates that the decrease in IPCE intensity observed when the device is transferred from the ambient atmosphere to $\mathrm{N}_{2}$ is faster for the IMEC device and slower for the NREL device in agreement with the presence of two $\left(\mathrm{ZnO}\right.$ and $\left.\mathrm{MoO}_{3}\right)$ and one $(\mathrm{ZnO})$ oxide layers respectively.

The second difference is related to the peak at $430 \mathrm{~nm}$ observed for the NREL devices and related to the bonding between the S-atom from the polymers and the $\mathrm{Ag}$ metal. Since the IMEC devices (ITO/ZnO/P3HT:PCBM/MoO $/ \mathrm{Ag} / \mathrm{Al}$ ) 

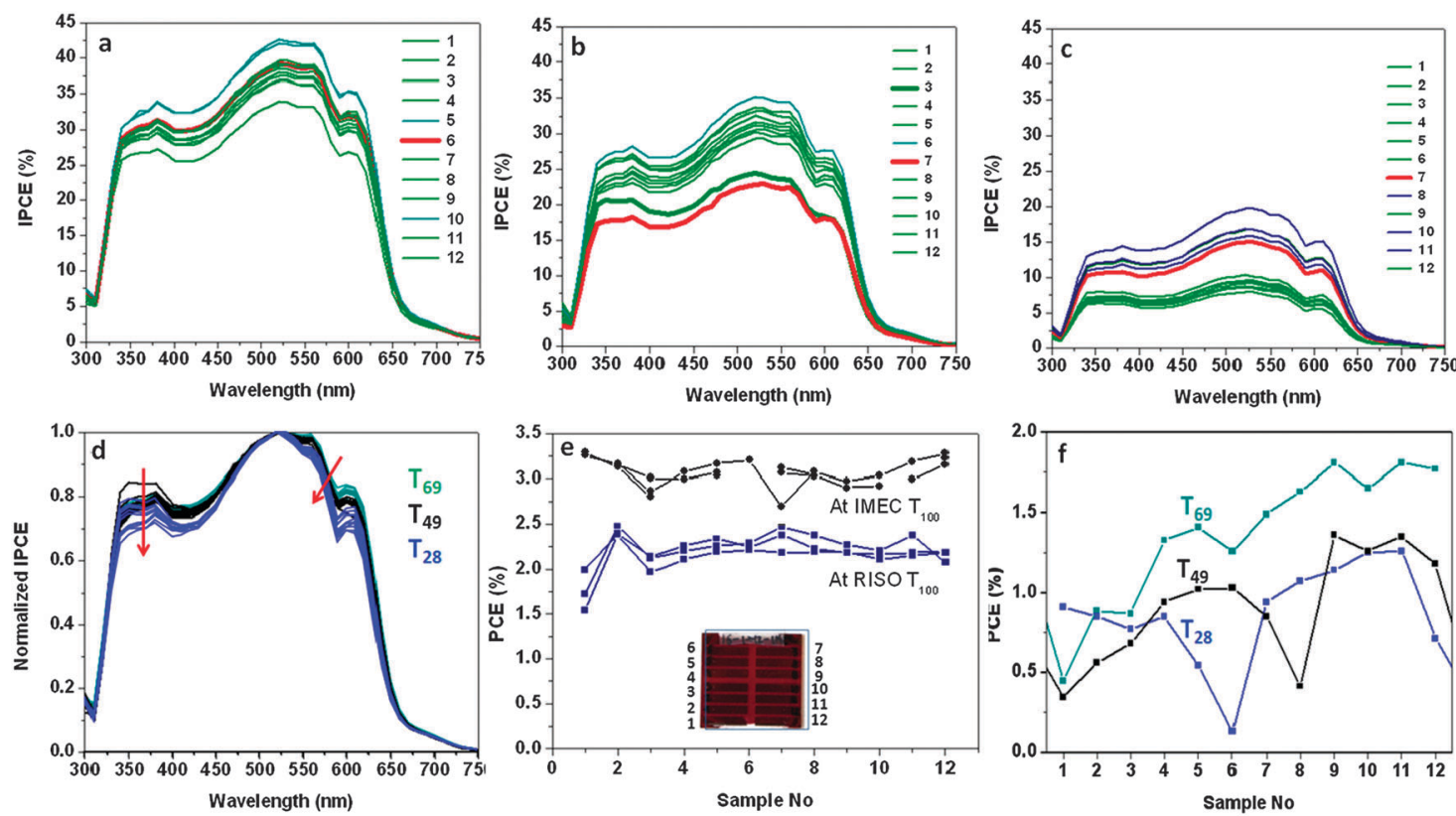

Fig. 22 IMEC substrates (12 solar cells per substrate) analyzed by the dark stability test at (a) $T_{69}$, (b) $T_{49}$ and (c) $T_{28}$. (a)-(c) IPCE, (d) Normalized IPCE, and (e) PCE of three reference devices analyzed at $T_{100}$. Analysis performed at IMEC right after device fabrication, at RISO-DTU after shipment at about $720 \mathrm{~h}$. In red the devices chosen at RISØ-DTU for the stability tests as reported in ref 1.
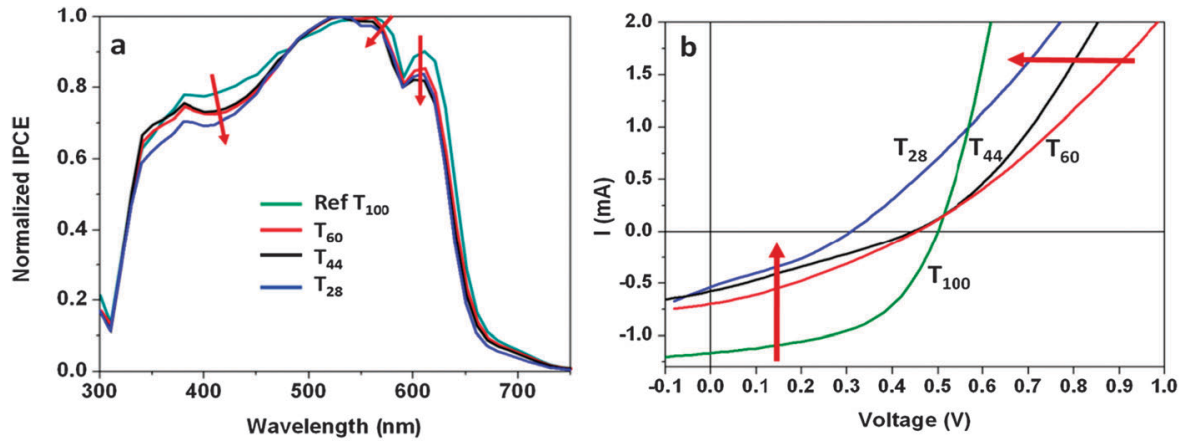

Fig. 23 Un-encapsulated IMEC solar cells under the full sun stability test. (a) PCE $v s$. time, (b) normalized IPCE analysis and (c) $I V$ curves. Data correspond to the full sun stabilization test at $T_{100}, T_{60}, T_{44}$ and $T_{28}$.
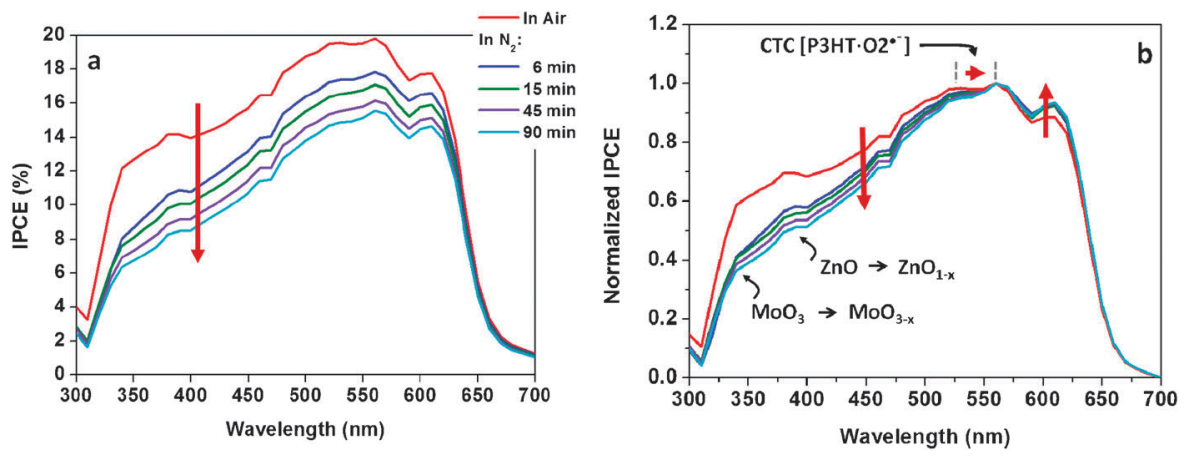

Fig. 24 in situ IPCE analysis of an IMEC device (a), and the corresponding normalized IPCE spectra (b).

do not have the PEDOT:PSS layer, the formation of a polymer-Ag bonding cannot take place, in agreement with the absence of the peak at $430 \mathrm{~nm}$ of the IPCE in Fig. 24b. Moreover, the formation of a bond between $\mathrm{P} 3 \mathrm{HT}$ and $\mathrm{Ag}$ cannot be possible since the $\mathrm{MoO}_{3}$ layer prevents this interaction.
In conclusion, for the IMEC devices, the replacement of the PEDOT:PSS layer by the $\mathrm{MoO}_{3}$ does not suppress the water intake completely but stabilizes the device enough to observe good reproducibility of the solar cells in the substrate. Water intake is driven by the oxides themselves that are sensitive to 
moisture and degrade the electrodes of the device. Nevertheless, the effect is observed to be slow and reproducible when compared with the NREL devices.

\section{Conclusions}

The IPCE spectra of an OPV can be considered as the fingerprint of the device since almost each of the materials that constitutes the solar cell can be identified in the spectra. Following the trail left by each peak during lifetime operation confers a general indication on the location of the problem in the materials. The true degradation of a solar cell should present IPCE spectra that lose all the peaks slowly over time in accordance with the decrease of the photovoltaic performance observed from the $I V$ curve. The latter was observed for the encapsulated samples or in samples opened to the ambient air and degraded in a short period of time. The semiencapsulated samples and un-encapsulated samples were observed to lose their PV properties randomly or suddenly. In some cases the main IPCE spectra were maintained unaffected and only changes in a specific wavelength region were observed. The response was attributed to the degradation of the device electrodes and charge transport layers which provokes a loss in current collection, but not the degradation of the OPV materials themselves. In conclusion, we found that the encapsulated devices are highly reproducible and stable, especially the small-molecule IAPP device. Encapsulated devices like HOLST and ISE showed that degradation could be initiated on the Ag or Au interface with PEDOT:PSS. The reaction between metals like $\mathrm{Ag}$, $\mathrm{Au}$ or $\mathrm{Cu}$ is known to be selfdriven and does not require the presence of oxygen or moisture from the atmosphere to initiate. The application of two different P3HT polymers to the RISØ-DTU devices demonstrates that a functionalized-P3HT confers higher stability and reproducibility to the solar cell. The un-encapsulated devices, NREL and IMEC, were demonstrated to be highly dependent on atmospheric conditions, and our results indicate that degradation of the devices, especially electrodes, started during shipment. Devices that used PEDOT:PSS as a hole extracting layer presented the worst cases of degradation attributed to its hygroscopic nature. The different PV behaviour observed for analyses taken at different laboratories has been attributed to the reversible water-uptake properties of PEDOT:PSS, and to a lesser extent to the semiconductor oxides $\mathrm{ZnO}$ and $\mathrm{MoO}_{3}$, that increase the electrode internal resistance at high humidity levels. The replacement of PEDOT:PSS by a thin layer of $\mathrm{MoO}_{3}$ improved device stability and slowed-down the sensitivity to moisture. However, it did not eliminate the effect of moisture uptake since semiconductor oxides are also known to be water-sensitive. The multi-device design of the un-encapsulated samples (NREL and IMEC), permitted us to arrive at important conclusions: (a) water uptake is observed in both devices, more strongly when PEDOT:PSS is used, but also due to the semiconductor oxides $\mathrm{ZnO}$ and $\mathrm{MoO}_{3}$; (b) water-uptake is observed to be random and reversible, (c) moisture degrades initially the electrodes of the device, and (d) the position of the solar cell within a module influences drastically the final solar cell degradation. The IPCE and the in situ IPCE techniques have been demonstrated to be useful as a first step towards the identification of the materials more susceptible to degradation during OPV stability tests.

\section{Acknowledgements}

This work has been supported by the Danish Strategic Research Council (2104-07-0022), EUDP (j.no. 64009-0050), and the Danish National Research Foundation. Partial financial support was also received from the European Commission as part of the Framework 7 ICT 2009 collaborative project HIFLEX (grant no. 248678), partial financial support from the EUIndian framework of the "Largecells" project that received funding from the European Commission's Seventh Framework Programme (FP7/2007-2013. grant no. 261936), partial financial support was also received from the European Commission as part of the Framework 7 ICT 2009 collaborative project ROTROT (grant no. 288565) and from PVERA-NET (project acronym POLYSTAR). To CONACYT (México) for the Ph.D. scholarship awarded to G. T.-E, to the Spanish Ministry of Science and Innovation, MICINN-FEDER project ENE2008-04373, to the Consolider NANOSELECT project CSD2007-00041, to the Xarxa de Referència en Materials Avançats per a l'Energia, XaRMAE of the Catalonia Government (Spain). RR and $\mathrm{HH}$ are grateful for financial support from the Thuringian Ministry of Culture and the German Federal Ministry of Education and Research in the frameworks of FIPV II and PPP (contract number 13N9843), respectively. DMT acknowledges generous support from the Inger and Jens Bruun Foundation through The AmericanScandinavian Foundation.

\section{References}

1 K. Norman, M. Jørgensen, S. A. Gevorgyan, T. Tromholt, B. Andreasen and F. C. Krebs, Adv. Mater., 2012, 24, 580-612.

2 D. M. Tanenbaum, M. Hermenau, E. Voroshazi, M. T. Lloyd, Y. Galagan, B. Zimmermann, M. Hösel, H. F. Dam, M. Jørgensen, S. A. Gevorgyan, S. Kudret, W. Maes, L. Lutsen, D. Vanderzande, U. Würfel, R. Andriessen, R. Rösch, H. Hoppe, G. Teran-Escobar, M. Lira-Cantu, A. Rivaton, G. Y. Uzunoğlu, D. Germack, B. Andreasen, M. V. Madsen, K. Norrman and F. C. Krebs, $R S C A d v$., 2012, 2, 882-893.

3 R. Rosch, D. M. Tanenbaum, M. Jørgensen, M. Seeland, M. Bärenklau, M. Hermenau, E. Voroshazi, M. T. Lloyd, Y. Galagan, B. Zimmermann, M. Hösel, H. F. Dam, S. A. Gevorgyan, S. Kudret, W. Maes, L. Lutsen, D. Vanderzande, U. Würfel, R. Andriessen, G. Teran-Escobar, M. Lira-Cantu, A. Rivaton, G. Y. Uzunoğlu, D. Germack, B. Andreasen, M. V. Madsen, K. Norrman, H. Hoppe and F. C. Krebs, Energy Environ. Sci., 2012, 5, 6521-6540.

4 J. Nelson, The Physics of Solar Cells, Imperial College Press, London, 2003.

5 G. Dennler, M. C. Schaber and C. Brabec, Adv. Mater., 2009, 21, 1323-1338.

6 M. Lira-Cantu, A. Chafiq, J. Faissat, I. Gonzalez-Valls and Y. Yu, Sol. Energy Mater. Sol. Cells, 2011, 95, 1362-1374.

7 X. Liu, Y. He, S. Wang and Q. Zhang, J. Alloys Compd., 2011, 509, S408-S411.

8 S. Morandi, G. Ghiotti, A. Chiorino and E. Comini, Thin Solid Films, 2005, 490, 74-80.

9 K. Shimura, H. Kanai, K. Utani, K. Matsuyama and S. Imamura, Appl. Catal., A, 2005, 283, 117-124.

10 G. Mestl, N. F. D. Verbruggen and H. Knözinger, Langmuir, 1995, 11, 3035-3041.

11 R. Lessmann, Z. Hong, S. Scholz, B. Maennig, M. K. Riede and K. Leo, Org. Electron., 2010, 11, 539-543. 
12 S. Schäfer, A. Petersen, T. A. Wagner, R. Kniprath, D. Lingenfelser, A. Zen, T. Kirchartz, B. Zimmermann, U. Würfel, X. Feng and T. Mayer, Phys. Rev. B: Condens. Matter Mater. Phys., 2011, 83, 16531.

13 L. Gaffo, M. R. Cordeiro, A. R. Freitas, W. C. Moreira, E. M. Girotto and V. Zucolotto, J. Mater. Sci., 2010, 45, $1366-1370$.

14 M. M. El-Nahass, H. M. Zeyada, M. S. Aziz and N. A. El-Ghamaz, Opt. Mater., 2004, 27, 491-498.

15 A. Gairola, G. V. Kunte, D. Chopra, T. N. G. Row, A. M. Umarji and S. A. Shivashankar, Polyhedron, 2010, 29, 2680-2688.

16 D. Shee and A. Sayari, Appl. Catal., A, 2010, 389, 155-164.

17 E. A. Meulenkamp, J. Phys. Chem. B, 1998, 102, 5566-5572.

18 A. B. Djurišić and Y. H. Leung, Small, 2006, 2, 944-961.

19 A. Sassara, G. Zerza and M. Chergui, PhysChemComm, 2001, 4, $1-3$.

20 A. Skumanich, Chem. Phys. Lett., 1991, 182, 486-490.

21 A. Balamurugan, K. C. Ho and S. M. Chen, Synth. Met., 2009, 159, 2544-2549.

22 K. J. Moreno, I. Wroggio, E. Arias, I. Llarena, S. E. Moya, R. F. Ziolo and H. Barrientos, J. Nanosci. Nanotechnol., 2009, 9, 3987-3992.

23 R. Pacios, R. Marcilla, C. Pozo-Gonzalo, J. A. Pomposo, H. Grande, J. Aizpurua and D. Mecerreyes, J. Nanosci. Nanotechnol., 2007, 7, 2938-2941.

24 G. Li, Y. Yao, H. Yang, V. Shrotriya, G. Yang and Y. Yang, Adv. Funct. Mater., 2007, 17, 1636-1644.

25 S. H. Cho and S. M. Park, J. Phys. Chem. B, 2006, 110, 25656-25664.

26 K. Hassan Bhuiyan and T. Mieno, Thin Solid Films, 2003, 441, 187-191.

27 M. S. A. Abdou, F. P. Orfino, Y. Son and S. Holdcroft, J. Am. Chem. Soc., 1997, 119, 4518-4524.

28 M. S. A. Abdou, F. P. Orfino, Z. W. Xie, M. J. Deen and S. Holdcroft, Adv. Mater., 1994, 6, 838-841.

29 Z. L. T. Fournier, T.-H. Tran-Thi, N. B. D. Houde, C. La Madeleine, R. Langlois, J. E. van Lier and D. Lexa, J. Phys. Chem. A, 1999, 103, $1179-1186$.

30 A. Twarowski, J. Chem. Phys., 1982, 77, 5840-5846.

31 A. Hamed, Y. Y. Sun, Y. K. Tao, R. L. Meng and P. H. Hor, Phys. Rev. B: Condens. Matter Mater. Phys., 1993, 47, 10874-10880.

32 S. Kment, P. Kluson, M. Drobek, R. Kuzel, I. Gregora, M. Kohout and Z. Hubicka, Thin Solid Films, 2009, 517, 5274-5279.

33 P. Day and R. J. P. Williams, J. Chem. Phys., 1962, 37, 567-570.

34 C. L. Huisman, A. Goossens and J. Schoonman, J. Phys. Chem. B, 2002, 106, 10578-10584.

35 M. M. El-Nahass, A. A. Atta, E. A. A. El-Shazly, A. S. Faidah and A. A. Hendi, Mater. Chem. Phys., 2009, 117, 390-394.

36 Q. L. Song, M. L. Wang, E. G. Obbard, X. Y. Sun, X. M. Ding, X. Y. Hou and C. M. Li, Appl. Phys. Lett., 2006, 89, 251118.
37 R. Taylor, J. P. Parsons, A. G. Avent, S. P. Rannard, T. J. Dennis, J. P. Hare, H. W. Kroto and D. R. M. Walton, Nature, 1991, 351, 277.

38 H. R. Kerp and E. E. Van Faassen, Chem. Phys. Lett., 2000, 332, $5-12$.

39 M. C. DeRosa and R. J. Crutchley, Coord. Chem. Rev., 2002, 233-234, 351-371.

40 M. Hermenau, K. Leo and M. Riede, Proc. SPIE, 2010, $77220-77222$.

41 G. Teran-Escobar, T. Belvin and M. Lira-Cantu, Submitted, 2012.

42 J. Liu, M. Agarwal, K. Varahramyan, E. S. Berney Iv. and W. D. Hodo, Sens. Actuators, B, 2008, 129, 599-604.

43 A. M. Nardes, M. Kemerink, M. M. de Kok, E. Vinken, K. Maturova and R. A. J. Janssen, Org. Electron., 2008, 9, 727-734.

44 E. Voroshazi, B. Verreet, A. Buri, R. Müller, D. Di Nuzzo and P. Heremans, Org. Electron., 2011, 12, 736-744.

45 K. Kawano, R. Pacios, D. Poplavskyy, J. Nelson, D. D. C. Bradley and J. R. Durrant, Sol. Energy Mater. Sol. Cells, 2006, 90, $3520-3530$.

46 K. Norrman, M. V. Madsen, S. A. Gevorgyan and F. C. Krebs, J. Am. Chem. Soc., 2010, 132, 16883-16892.

47 J. J. Steele, M. T. Taschuk and M. J. Brett, IEEE Sens. J., 2008, 8, $1422-1429$.

48 Y. Qiu and S. Yang, Adv. Funct. Mater., 2007, 17, 1345-1352.

49 T. S. Sian and G. B. Reddy, Chem. Phys. Lett., 2006, 418, 170-173.

50 Z. Chen and C. Lu, Sens. Lett., 2005, 3, 274-295.

51 S. Pokhrel and K. S. Nagaraja, Phys. Status Solidi A, 2003, 198, 343-349.

52 B. Ecker, J. C. Nolasco, J. Pallarés, L. F. Marsal, J. Posdorfer, J. Parisi and E. Von Hauff, Adv. Funct. Mater., 2011, 21, $2705-2711$.

53 M. Manceau, A. Rivaton, J. L. Gardette, S. Guillerez and N. Lemaître, Sol. Energy Mater. Sol. Cells, 2011, 95, 1315-1325.

54 T. Stubhan, T. Ameri, M. Salinas, J. Krantz, F. MacHui, M. Halik and C. J. Brabec, Appl. Phys. Lett., 2011, 98, 253308.

55 L. Hou, E. Wang, J. Bergqvist, B. V. Andersson, Z. Wang, C. Müller, M. Campoy-Quiles, M. R. Andersson, F. Zhang and O. Inganäs, Adv. Funct. Mater., 2011, 21, 3169-3175.

56 M. Lira-Cantu, K. Norrman, J. W. Andreasen, N. Casan-Pastor and F. C. Krebs, J. Electrochem. Soc., 2007, 154, B508-B513.

57 M. Lira-Cantu, K. Norrman, J. W. Andreasen and F. C. Krebs, Chem. Mater., 2006, 18, 5684-5690.

58 M. Lira-Cantu and F. C. Krebs, Sol. Energy Mater. Sol. Cells, 2006, 90, 2076-2086.

59 M. Lira-Cantu, M. Khoda Siddiki, D. Muñoz-Rojas, R. Amade and N. I. González-Pech, Sol. Energy Mater. Sol. Cells, 2010, 94, $1227-1234$.

60 J.-H. Lee, D.-S. Leem, H.-J. Kim and J.-J. Kim, Appl. Phys. Lett., 2009, 94, 123306.

61 P. R. G. Mestl, B. Delmon and H. Knozinger, J. Phys. Chem., 1994, 98, 11269-11275. 